\title{
Properties of HVOF-sprayed Stellite-6 coatings
}

Paolo Sassatelli ${ }^{1,}$, Giovanni Bolelli ${ }^{1, *}$, Magdalena Lassinantti Gualtieri ${ }^{1}$, Esa Heinonen ${ }^{2}$, Mari Honkanen $^{3}$, Luca Lusvarghi ${ }^{1,4}$, Tiziano Manfredini ${ }^{1,4}$, Rinaldo Rigon ${ }^{5}$, Minnamari Vippola ${ }^{3}$

${ }^{1}$ Department of Engineering “Enzo Ferrari”, University of Modena and Reggio Emilia, Via Pietro Vivarelli 10/1, 41125 Modena (MO), Italy

${ }^{2}$ Center of Microscopy and Nanotechnology, University of Oulu, P.O. Box 8000, 90014 University of Oulu, Finland

${ }^{3}$ Materials Science, Tampere University of Technology, P.O. Box 589, 33101 Tampere, Finland

${ }^{4}$ Consorzio Interuniversitario Nazionale per la Scienza e Tecnologia dei Materiali (INSTM), Local Unit Università di Modena e Reggio Emilia, Via Pietro Vivarelli 10/1, 41125 Modena (MO), Italy

${ }^{5}$ Ecor Research S.p.A., Via Friuli 11, 36015 Schio (VI), Italy

* Corresponding author: tel.: +39 0592056233; fax: +39 0592056243; e-mail: giovanni.bolelli@unimore.it

$\S$ Present address: Il Sentiero International Campus S.r.l., Via Friuli 11, 36015 Schio (VI), Italy

\footnotetext{
Abstract

Stellite-6 coatings were deposited onto AISI 304 stainless steel substrate by gas-fueled HVOF spraying, systematically varying the process parameter settings.

By operating the HVOF torch with a fuel-rich mixture, dense coatings ( $<1 \%$ porosity) are produced, containing up to $\approx 3 \mathrm{vol} . \%$ oxide inclusions. A substantial amount of a Cr-rich f.c.c. phase is found, mainly produced by quenching of molten lamellae, and distinct from the equilibrium, Co-based f.c.c. solid solution retained in unmelted particles. These coatings exhibit pseudo-passive behavior and survive 5 cycles $(100 \mathrm{~h})$ of the Corrodkote test (ASTM B380-97) with no substrate corrosion. Coatings obtained from oxygen-rich mixtures, on the
} 
other hand, contain fewer oxide inclusions but also greater porosity, and do not protect the substrate against corrosion.

The wear behavior of the coatings is less influenced by deposition conditions. In ball-on-disk dry sliding tests, all coatings exhibit wear rates of $2-3 \times 10^{-5} \mathrm{~mm}^{3} /(\mathrm{N} \cdot \mathrm{m})$, higher than those reported for bulk or clad Stellite, because of interlamellar delamination. Strain-induced, "martensitic" phase transformation from the f.c.c. structure to a h.c.p. one is observed over a 1 $-2 \mu \mathrm{m}$ depth below the contact surface. Additional tribo-oxidation is onset when frictional heat dissipation has heated the wear debris enough to trigger its reaction with the environment. Correspondingly, a transition to a regime of higher friction occurs (from $\approx 0.6$ to $\approx 0.8$ ). At $400{ }^{\circ} \mathrm{C}$, lamellar delamination is suppressed but wear rates rise to $5-8 \times 10^{-5}$ $\mathrm{mm}^{3} /(\mathrm{N} \cdot \mathrm{m})$ because of abrasive and adhesive wear. At $800^{\circ} \mathrm{C}$, a dense "glaze" tribofilm is formed by sintered debris particles, firmly bonded to a thermally grown oxide scale on the underlying metal surface. The "glaze" protects the coating, lowering the wear rate to $\approx 1 \times 10^{-5}$ $\mathrm{mm}^{3} /(\mathrm{N} \cdot \mathrm{m})$ and the friction coefficient to $<0.45$. Under high-stress particle abrasion conditions, wear rates of $\approx 1 \times 10^{-3} \mathrm{~mm}^{3} /(\mathrm{N} \cdot \mathrm{m})$ are found.

Key-words: Stellite coating; High Velocity Oxygen-Fuel (HVOF); Dry particles abrasion; Sliding wear; High-temperature tribology; Electrochemical corrosion test. 


\section{Introduction}

Developed in the early 1900s with the aim to provide high-temperature strength, Co-CrW(Mo)-C alloys belonging to the Stellite family nowadays find numerous industrial applications for wear and/or corrosion protection [1]. The ability to develop Cr-based oxide layers indeed confers these alloys good resistance against oxidation at moderate to high temperatures and against corrosion at room temperature, which is further improved by alloying elements such as W and/or Mo [1]. Moreover, their peculiar tribological properties include high hot hardness and remarkable galling resistance, which allows Stellite alloys to sustain higher contact pressures than most other metal alloys [1].

In bulk form [2-8] or as cladded overlays, deposited by such techniques as metal arc or TIG welding [5], PTA cladding [9], and laser cladding [7,10,11], the microstructure of Stellite alloys consists of a f.c.c. Co-based matrix containing Cr-based carbide phases [1]. In hypoeutectic alloys such as Stellite-6 or Stellite-12, for instance, primary f.c.c. Co-based dendrites are separated by an eutectic phase containing carbides based on $\mathrm{M}_{7} \mathrm{C}_{3}[1,3,4,7,9]$ and $\mathrm{M}_{23} \mathrm{C}_{6}$ [9] or $\mathrm{M}_{12} \mathrm{C}$ [4]. Although the exact microstructural features have a significant effect on the eventual wear resistance [4], a fundamental understanding of their tribological behavior can be inferred from the extant literature:

1) At room temperature, the wear resistance of Stellite alloys depends, on the one hand, on the carbide phases, which protect the surrounding matrix under sliding and abrasive wear conditions. Material loss follows from fracturing, fragmentation and/or pull-out of carbides, a mechanism that is largely dependent on their size, shape and distribution. For instance, large carbides support effectively the abrasive contact with hard particles and/or the sliding contact with counterbody asperities, but they also induce greater brittleness. Fine carbides, on the other hand, enhance toughness, but they can be so much smaller than the abrasive groove size that they are removed together with the matrix [4,5]. 
On the other hand, the matrix also undergoes plastic deformation during sliding or abrasion, either through shearing $[2,12]$ or through mild or coarse grooving $[10,12]$, depending on contact conditions (contact pressure, speed, lubrication regime, etc.). Plastic deformation of the Co-based f.c.c. phase brings about a "martensitic" transformation to a h.c.p. structure $[2,13]$, due to the low f.c.c. $\rightarrow$ h.c.p. stacking fault energy typical of CoCr-based alloys [15]. This leads to the formation of a surface tribo-layer consisting of aligned h.c.p. crystals $[2,11]$. Under these conditions, wear only proceeds through the delamination of the tribo-layer, once enough contact damage has been accumulated [2,7]. This process plays an important role both for wear resistance, as the martensitic transformation promotes work hardening of the tribo-layer [13], and for friction reduction [15]. It is therefore a key factor for the mentioned high galling resistance of Stellite alloys $[2,11,13]$.

2) As temperature increases, a loss of hardness in the matrix phase [16] causes a decline in wear resistance until $300-500{ }^{\circ} \mathrm{C}$. Further increases in temperature, by contrast, improve the wear resistance as tribo-oxidation phenomena favor the formation of a protective oxide "glaze" onto the alloy surface $[8,9,17]$.

The deep knowledge on the corrosion and tribology of bulk or clad Stellites, as reviewed above, is not matched by the few studies on the properties of thermally-sprayed Stellite coatings, although the latter find numerous applications e.g. in pump parts, valves, extruders, etc. $[18,19]$. The peculiar lamellar microstructure of these coatings [20] implies that their wear behavior will often differ from that of the corresponding bulk material [21]. Research on the mechanical and tribological properties of HVOF-sprayed Stellite has been carried out by Houdková et al. [22-25], as well as by some other authors [26-31], who provided information on sliding and abrasive wear resistance at room temperature and on the effects of post processing (e.g. heat treatment, laser remelting). The amount of available data is however scarce, the wear mechanisms still need to be clarified in detail, and almost nothing is known 
on wear at high temperatures. A series of studies in high-temperature environments are available, but these were exclusively devoted to hot corrosion in boiler environments [32-35]. It is therefore the purpose of this paper to compensate for these shortcomings by: (i) studying the effect of process parameters on the properties of Stellite- 6 coatings deposited by gasfueled HVOF spraying; (ii) investigating their corrosion behavior in aqueous environment; (iii) providing a detailed tribological analysis under various conditions (abrasion and sliding) and at different temperatures (R.T., $400{ }^{\circ} \mathrm{C}, 800{ }^{\circ} \mathrm{C}$ ).

\section{Experimental}

\subsection{Sample manufacturing}

A Co-based gas atomized powder (similar to Stellite 6), with nominal particle size distribution $-53+20 \mu \mathrm{m}$ and nominal chemical composition (in wt.\%) $28.5 \mathrm{Cr}, 4.4 \mathrm{~W}, 1.5 \mathrm{Fe}, 1.5 \mathrm{Ni}, 1.1 \mathrm{C}$, 1Si and balance Co, was chosen for this study (Co-based 2637-02, Höganäs, Bruksgatan, Sweden). AISI 304 stainless steel plates of $150 \times 25 \times 3 \mathrm{~mm}$ size were used as substrates. Steel plates were sandblasted with alumina to achieve a surface roughness of $\mathrm{Ra} \approx 6 \mu \mathrm{m}$. After sandblasting, samples were cleaned in an ultrasound bath with acetone for 5 minutes, and dried with compressed air. Cleaned samples were vacuum packed and conserved in a dryer at $60{ }^{\circ} \mathrm{C}$ until coating deposition. The deposition was performed using an HVOF Diamond Jet 2600 hybrid gun (Oerlikon Metco, Wohlen, Switzerland), fueled with hydrogen.

The effect of the spraying parameters on coating properties was evaluated by changing the powder feed rate, the oxygen flow rate and the hydrogen flow rate according to a screening factorial design as reported in Table 1 . The spraying parameters suggested by the manufacturer were used as the center (Central Point, C.P.) of the studied range. All other spraying parameters were kept constant at the manufacturer's suggested value, as reported in Table 2. 


\subsection{Test samples preparation}

Suitable samples for testing were obtained from the coated plates using standard metallographic techniques.

Samples were cut with metallographic saw using resin-bonded alumina blades under continuous lubricant flow, taking care to maintain the coatings under compression during cutting.

The cross-sections of the samples, for scanning electron microscope (SEM) analysis and micro-indentation tests, were obtained by embedding cut specimens in a room temperaturesetting epoxy resin. The resins were ground with $\mathrm{SiC}$ abrasive papers having progressively finer abrasive size (400, 800, 1000, 2500 mesh), and then polished with diamond paste $(3 \mu \mathrm{m})$ and colloidal $\mathrm{SiO}_{2}$ suspension.

For the dry sliding wear tests and the electrochemical corrosion tests, coated specimens of $25 \times 25 \mathrm{~mm}$ size were polished using the same procedure described above, to achieve a surface roughness $(\mathrm{Ra})$ below $0.1 \mu \mathrm{m}$.

For the dry sand abrasion test, coated specimens of $100 \times 25 \mathrm{~mm}$ size were used in as-sprayed conditions.

Before each test, the specimens were cleaned using an ultrasonic bath with acetone for 5 minutes, and dried with compressed air.

The cross-section of the powder for SEM analysis was obtained mixing approximately $1 \mathrm{~cm}^{3}$ of powder with a room temperature-setting epoxy resin, as to obtain a homogenous composite. The composite surface was polished following the procedure described above, resulting in the sectioning of superficial particles.

\subsection{Feedstock powder and coating characteristics}

The particle size distribution of the feedstock powder was measured with the laser diffraction method, using water as dispersion medium (Mastersizer 2000, Malvern Instruments, Malvern, 
UK). Simultaneous differential thermal analysis and thermo-gravimetric analysis (DTA / TG:

STA409, Netzsch, Selb, Germany) were also performed on the powder in a temperature range from room temperature $\left(\approx 25^{\circ} \mathrm{C}\right)$ to $1000{ }^{\circ} \mathrm{C}$, applying a heating rate of $10{ }^{\circ} \mathrm{C} / \mathrm{min}$, in an alumina crucible in air.

The surface and cross-section of the powder, as well as the coating cross sections, were analyzed using an SEM (Nova NanoSEM-450, FEI, Eindhoven, NL) equipped with energy dispersive X-Ray (EDX) spectroscopy (Quantax-200, Bruker Nano GmbH, Berlin, Germany). The coating thickness was measured on 200x magnified SEM micrographs randomly acquired along the cross-section, using an image analysis software (Image - NIH, Bethesda, Maryland, USA). All values are the average of 5 measurements. The same software was used to measure the coating porosity, as an average of 10 measurements on $2000 \times$ magnified micrographs randomly acquired on the coatings' cross-section.

X-Ray diffraction (XRD) analysis was performed on both the powder and the as-sprayed coatings (X-Pert PRO, PANAlytical, Almelo, NL), using $\mathrm{Cu}-\mathrm{K} \alpha$ radiation emitted from a conventional X-ray tube operated at $40 \mathrm{kV}$ and $40 \mathrm{~mA}$. Measurement conditions included a $20^{\circ}-100^{\circ} 2 \theta$ angular range, with a scan step of $0.017^{\circ}$ and a dwell time of $180 \mathrm{~s} / \mathrm{step}$. A proportional gas counter with a single-crystal monochromator was used to suppress the fluorescence background. Patterns were analyzed using the HighScore Plus (PANAlytical) software. XRD data was elaborated using Rietveld refinement in order to identify compositional trends of the coatings induced by changing the spraying conditions. The refinements were accomplished with the GSAS software [36] and its graphical interface EXPGUI [37]. Peak profiles were modeled using one Gaussian (isotropic size) and two Lorentzian (isotropic size and strain broadening) profile terms in a multi-term Simpson's rule integration of the pseudo-Voigt function. The zero shift, background (Chebyshev function with 9 terms) and scale factors were refined together with the unit cell parameters of the newly formed phases. The profile parameters for these phases were fixed to the values 
obtained for the f.c.c. cobalt-rich solid solution alloy composing the feedstock powder, except for the Lorentzian profile term describing the isotropic size broadening (LX in GSAS), which was refined.

Depth-sensing micro-indentation (Micro-Combi Tester, Anton-Paar TriTec, Peseux - CH) and nano-indentation (NHT, Anton-Paar TriTec) tests were carried out on the coatings' crosssection using a Berkovich indenter under a load of $3 \mathrm{~N}$ (loading/unloading rate $4.5 \mathrm{~N} / \mathrm{min}$ ) and $10 \mathrm{mN}$ (loading/unloading rate $15 \mathrm{mN} / \mathrm{min}$ ) respectively. A minimum of 20 microindentations and 50 nano-indentations were performed on each coating. Measurement procedures (including indenter calibration) and load-penetration data analysis were performed in accordance with the ISO 14577 standard.

\subsection{Tribological tests}

Dry sliding wear ball-on-disk tests in unidirectional rotation configuration (ASTM G99-05) were performed on polished coating surfaces. Six samples per each set of spraying parameters were tested, two at room temperature $\left(\approx 25^{\circ} \mathrm{C}\right.$ and $\approx 60 \%$ R.H. $)$, two at $400^{\circ} \mathrm{C}$ and two at 800 ${ }^{\circ} \mathrm{C}$. Alumina spheres of $6 \mathrm{~mm}$ diameter were employed as counterparts. As previously explained in $[38,39]$, this choice is justified, on the one hand, by the fact that $\mathrm{Al}_{2} \mathrm{O}_{3}$ counterparts mimic the frequent occurrence of wear by hard asperities (e.g. hard phases embedded in the counterbody, foreign particles, oxidized wear debris), and, on the other hand, by the hot hardness and chemical stability of $\mathrm{Al}_{2} \mathrm{O}_{3}$, which allow wear testing at high temperature without introducing uncontrolled, additional tribochemical interactions. Samples were mounted on a rotating sample holder closed into a furnace to control the temperature. The $\mathrm{Al}_{2} \mathrm{O}_{3}$ counterpart, held at $7 \mathrm{~mm}$ from the rotational axis of the sample, was pressed against the coating surface with a constant normal load of $5 \mathrm{~N}$. The sample was rotated to achieve a relative sliding speed of $0.2 \mathrm{~m} / \mathrm{s}$, for a total sliding distance of $2500 \mathrm{~m}$. A 
calibrated load cell mounted on the pin holder is used to monitor the tangential force (hence, the friction coefficient) during the test.

Surface profiles of the wear tracks, obtained using a non-contact, structured-light profilometer (Confovis profilometer mounted on a Nikon Eclipse LV150N optical microscope) were used to evaluate the volume loss of the samples, while optical microscopy was used to evaluate the worn cap diameter of the counterpart. Wear rates were then calculated as the ratio between the volume loss (measured in $\mathrm{mm}^{3}$ ) and the product of total sliding distance (m) and applied load $(\mathrm{N})$.

The dry sliding wear mechanisms were studied by SEM+EDX analyses (Nova NanoSEM-450 with Quantax-200 EDX system) of the surfaces and cross-sections of the wear tracks. Crosssections were obtained by vacuum-mounting the worn samples in a room temperature-setting epoxy resin before metallographic cutting and grinding/polishing as described in Section 2.2, in order to prevent removal of surface layers. The composition of any tribofilm formed on the worn surfaces was also analyzed by micro-Raman spectroscopy (LabRam, Horiba JobinYvon, Longjumeau - FR) using a $532.81 \mathrm{~nm}$-wavelength laser focused through a 100× objective.

The crystal structure of the coating was studied after the ball-on-disk dry sliding wear test by transmission electron microscopy (TEM). Two TEM samples were prepared from both outside and inside the wear track, by focused ion beam scanning electron microscope (FIBSEM, Helios DualBeam, FEI, Eindhoven, NL). A platinum protective layer was deposited on the sample surfaces prior to the FIB milling. After the milling, the thin lamellas were placed with a micromanipulator on the TEM lift-out copper grid. Bright field (BF) images and selected area electron diffraction (SAED) patterns were collected by TEM (JEM-2010, JEOL Ltd., Tokyo, Japan). 
Moreover, dry sand steel-wheel tests were performed on the coating surface in as-sprayed conditions following a modified version of the ASTG G65-2016 abrasion test. In this test, the coating surface is pressed against a steel wheel with a constant load $40.2 \mathrm{~N}$. The Fe360 steel wheel rotates at a constant speed of $85 \mathrm{rpm}$, while a continuous stream of $\mathrm{Al}_{2} \mathrm{O}_{3}$ sand $(64.1 \pm$ $3.4 \mathrm{~g} / \mathrm{min}$ ) flows between the sample surface and the wheel. The steel wheel has a diameter of $200 \mathrm{~mm}$ and a thickness of $10 \mathrm{~mm}$. The alumina sand as an average particle size distribution of $201 \mu \mathrm{m}$ (FEPA-80). Tests were performed with a total of 200 rotations of the steel wheel, for a total sliding distance of $125.66 \mathrm{~m}$. A minimum of 5 tests were performed on each coating obtained with a different set of spraying parameters. The volume loss from the wear scars was measured on surface profiles acquired with a white light confocal microscope (CHR150, Stil, Aix-en-Provence, France) and was converted to wear as mentioned above. The abrasion wear mechanisms were studied by SEM+EDX analysis of the wear tracks.

\subsection{Corrosion tests}

Two polished samples for each set of spraying parameters were subjected to an electrochemical polarization corrosion test. Tests were performed at room temperature $(\approx 25$ ${ }^{\circ} \mathrm{C}$ ), in a three-electrode cell containing $300 \mathrm{ml}$ of a $0.1 \mathrm{M} \mathrm{HCl}$ aqueous solution in aerated condition, using an $\mathrm{Ag} / \mathrm{AgCl} / \mathrm{KCl}_{\text {(sat) }}$ reference electrode and a platinum grid as counter electrode. The sample was connected to the working electrode and $1 \mathrm{~cm}^{2}$ of its surface was exposed to the solution through a calibrated PTFE gasket. The polarization tests started after one hour of free corrosion in order to stabilize the open circuit potential (OCP). Tests were performed by scanning an overpotential range from $-400 \mathrm{mV}$ vs. OCP to $+1400 \mathrm{mV}$ vs. OCP, at a scanning rate of $0.5 \mathrm{mV} / \mathrm{s}$. Cathodic (from $-400 \mathrm{mV}$ vs. OCP to OCP) and anodic (from OCP to $+1400 \mathrm{mV}$ vs. OCP $)$ polarization curves were reported in a $\left[\log \left(\mathrm{I} / \mathrm{A} / \mathrm{cm}^{2}\right)\right.$ vs. V] diagram (Evans diagram), where the logarithm of the current density (measured in $\mathrm{A} / \mathrm{cm}^{2}$ ) was on the ordinates, and the potential (in V) was on the abscissas. The Tafel fitting method 
$[40,41]$ was used to obtain the corrosion current density $\left(\mathrm{I}_{\text {corr }}\right)$ and the corrosion potential $\left(\mathrm{E}_{\text {corr }}\right)$.

Three specimens, chosen as those with the lowest porosity (see Section 2.3) were also subjected to a Corrodkote test, following the ASTM B380-97(2013) standard. $50 \mathrm{ml}$ of a corrosive aqueous solution composed of $0.7 \mathrm{~g} / \mathrm{l}$ cupric nitrate $\left(\mathrm{Cu}\left(\mathrm{NO}_{3}\right)_{2} \cdot 3 \mathrm{H}_{2} \mathrm{O}\right), 1.98 \mathrm{~g} / \mathrm{l}$ ferric chloride $\left(\mathrm{FeCl}_{3} \cdot 6 \mathrm{H}_{2} \mathrm{O}\right)$ and $20 \mathrm{~g} / \mathrm{l}$ ammonium chloride $\left(\mathrm{NH}_{4} \mathrm{Cl}\right)$ are mixed with $30 \mathrm{~g}$ of ceramic grade kaolin. The slurry is applied on the coating surface using a dropper. The edges of the coated samples are protected using silicon glue, to avoid the direct contact of the corrosive slurry with the stainless steel substrate. Once covered with the corrosive slurry, the samples are maintained at constant temperature $\left(38 \pm 2^{\circ} \mathrm{C}\right)$ and constant humidity (90\% R.H.) for 20 hours. At the end of the 20 hour-cycle, the corrosive paste is removed from the sample surface with flowing water, taking care not to remove the corrosion products. Samples are dried with compressed air and then visually inspected to evaluate the presence of corrosion products. The test is repeated for 5 complete cycles, for a total corrosion time of 100 hours.

\section{Results and discussion}

\subsection{Powder characterization}

Based on SEM micrographs (Figure 1A-C), the powder shows the classical morphology of a gas atomized metal, with spherical particles sometimes surrounded by satellites. Their actual size distribution, characterized by $\mathrm{d}_{0.1}=29 \mu \mathrm{m}, \mathrm{d}_{0.5}=41.6 \mu \mathrm{m}$, and $\mathrm{d}_{0.9}=59.3 \mu \mathrm{m}$, is considerably coarser compared to the nominal range provided by the supplier (Section 2.1). On their cross section (Figure 1B), the particles appear dense and homogeneous, and no secondary phases or precipitates could be observed. The EDX spectra acquired on different particles show the presence of $\mathrm{Co}, \mathrm{Cr}, \mathrm{W}, \mathrm{C}$, as well as of minor amounts of $\mathrm{Fe}$ and $\mathrm{Si}$, confirming the nominal elemental composition provided by the manufacturer (Figure 1D). 
Dendrites, radially oriented from the surface to the center of the particles, can be clearly observed in magnified pictures (Figure 1C); based on the XRD pattern (Figure 2), they consist of an f.c.c. Co-based solid solution. Despite the apparent absence of secondary phases in the SEM micrographs, the XRD pattern also shows a very low intensity peak, identifiable as $\mathrm{M}_{7} \mathrm{C}_{3}$ carbides (mainly $\mathrm{Cr}_{7} \mathrm{C}_{3}$ ). The presence of this carbide agrees with the $\mathrm{Co}-\mathrm{Cr}-\mathrm{C}$ phase diagram, which foresees the equilibrium between $\mathrm{M}_{7} \mathrm{C}_{3}$ and $\gamma$-Co solid solution for a theoretical composition of $\mathrm{Co}-28 \% \mathrm{Cr}-1.1 \% \mathrm{C}$ (quantities in wt. \%) [42]. The amount of $\mathrm{M}_{7} \mathrm{C}_{3}$ type carbides expected for the Stellite- 6 composition should be approximately $13 \%$ [1]. According to Kong et al. [20], the impossibility to see the carbide precipitates in the SEM micrographs suggests a lower carbide fraction, estimated by the authors to be around $5 \mathrm{wt} . \%$. The authors also suggest that the particle size distribution of the precipitates should be in the nanometer range. The observed lower carbide content, compared to the theoretical one, can be attributed to the high cooling rate experienced by the melted alloy during the gas atomization process, estimated up to $10^{5}{ }^{\circ} \mathrm{C} \cdot \mathrm{s}^{-1}$ for particles with diameter below $100 \mu \mathrm{m}$ [43]. These cooling conditions can restrain the precipitation of secondary phases.

The TG-DTA curves reported in Figure 3 show high thermal stability in an oxidizing environment. The powder remains almost unaltered up to $750^{\circ} \mathrm{C}$. Above this temperature, the presence of a slight exothermic peak accompanied with a small weight gain indicates the onset of oxidation reactions.

\subsection{Microstructure and phase composition of the coatings}

The microstructure and the phase composition of the coatings is strongly influenced by the used deposition parameters. In particular, a correlation was found between to the equivalence ratio $\lambda$, defined in equation (1), and the coating characteristics. The equivalence ratio $\lambda$ represents the deviation from the stoichiometric combustion, considering the fuel and oxygen 
flow rates in the spraying gun (including the fraction of oxygen included in the air flow - see Table 2). Thus, $\lambda$ is directly related to the flame temperature as reported by [44-47].

$$
\lambda=\left(\frac{O_{2} \text { Flow rate } / \mathrm{H}_{2} \text { Flow rate }}{\text { Stoichiometric ratio }}\right)
$$

Higher flame temperatures are expected close to the stoichiometric condition $(\lambda=1)$ or with slight fuel excess $(\lambda<1)$. In particular, coatings sprayed with $\lambda$ values close to $\lambda \approx 0.85$ (parameter sets 1 and 6, Table 1), corresponding to the maximum adiabatic temperature of a hydrogen/oxygen flame [48], appear much denser than the others, with well flattened and well bonded lamellae (Figure 4). This is confirmed by average values of coating porosity $<1 \%$, as summarized in Table 3. Differently, parameter sets 4 and $5(\lambda>1$, Table 1$)$ lead to a porous microstructure (porosity $>2 \%$, Table 3 ), and numerous rounded particles can be recognized on their cross-section (Figure 4), testifying to their low degree of melting and deformation upon impact. Accordingly, magnified views (Figure 5 - see the unmolten particle labelled in the section of sample Run5) show that rounded particles maintained the dendritic structure of the feedstock powder, without major modifications, confirming that they were heated below the melting temperature during spraying.

To the contrary, when hotter flame parameters were used (Figure 5), flattened lamellae exhibit very fine equiaxed or columnar grains, similar to those characterized by TEM in [20], indicating that the corresponding, original powder particles were fully melted during spraying. During subsequent re-solidification, these particles experienced either homogeneous nucleation inside their volume or heterogeneous nucleation along the bottom face in contact with underlying material, leading to the observed grain structures.

The XRD patterns acquired on the coatings differ from that of the feedstock powder (Figure 2) not only because the peaks of the main f.c.c.-Co phase appear slightly broader, but also 
because clear peak splitting occurs. This means two main phases actually exist in the coatings: one is the same f.c.c. Co-based solid solution already identified in the powder, while the other appears as another f.c.c. Co-based solid solution, richer in $\mathrm{Cr}$, which has slightly larger lattice parameters compared to the former. The presence of two distinguishable solid solutions in the coatings can be ascribed to particles' melting within the flame and to the extremely high cooling rates $\left(10^{5} \div 10^{8}{ }^{\circ} \mathrm{C} / \mathrm{s}[49]\right)$ subsequently experienced by the fully melted particles when impacting onto the cold substrate. Indeed, the $\mathrm{Cr}$-rich $\mathrm{M}_{7} \mathrm{C}_{3}$ phase is no more visible in the XRD patterns of the coatings, as already observed by other authors $[20,24]$, presumably because it was entirely dissolved in the melt and its re-precipitation was hindered by impactquenching. As a result, a Cr-enriched solid solution is developed as seen in the XRD patterns. Apparently, this is the main constituent of the very fine-grained structure seen in molten lamellae (Figure 5). This finding is consistent with the known tendency to form metastable phases in thermal spray coatings [50].

On the other hand, unmelted particles, which still exhibit the original, dendritic structure, also retain the Co-based f.c.c.-phase. Their content of residual $\mathrm{M}_{7} \mathrm{C}_{3}$ phase presumably falls below the detection limit of the XRD technique.

The quantification of crystalline phases through the Rietveld refinement further pointed out to a clear trend in the content of the two f.c.c. solid solutions as a function of the equivalence ratio $\lambda$ (Figure 6A). In particular, the ratio between the mass fractions of the Co-rich and $\mathrm{Cr}$ rich solid solutions decreases with decreasing $\lambda$, with an almost linear trend (Figure 6A). Being the Cr-rich metastable phase presumably formed by quenching of the fully melted particles, its amount increases as the coating contains a higher number of molten lamellae because of increasing flame temperature $(\lambda<1)$.

The XRD patterns of the coatings also show the presence of a small amount of Cr-Co based oxides (Figure 2). These are visible in the cross-section SEM micrographs, Figure 5, and in 
the corresponding EDX spectra, Figure 7 . Their overall content is $<3 \%$ in all coatings; however, a clear trend of increasing amount of oxides is seen with decreasing $\lambda$ (Figure 6B). A low equivalence ratio $\lambda$ provides a reducing flame stoichiometry; hence, oxidation is not due to interaction with the process gases, but to reaction with the atmosphere. The fact that oxides mostly appear as thin, dark layers at the boundary between lamellae (see the areas marked as "spectrum 2" and "spectrum 3" in Figure 5 and the corresponding EDX spectra in Figure 7) confirms their formation occurred immediately after deposition, during the brief period when the lamella was still hot enough to react with surrounding air, according to the mechanisms laid out in [51]. The increased flame temperature at low $\lambda$ values means that more particles were heated above their melting point and that more heat was delivered to the sample surface: both factors enhanced the described reactivity.

The equivalence ratio $\lambda$ also affects the deposition efficiency. Indeed, considerable differences in coating thickness emerge within the couples of samples Run1 - Run5 and Run4 - Run6, deposited using the same powder feed rate but different $\lambda$ values (Table 3). In particular, coatings deposited with $\lambda<1$ (Run1 and Run6) are almost twice as thick as the corresponding coatings deposited with $\lambda>1$, indicating that hotter conditions increase the deposition efficiency of up to $50 \%$.

Despite the above described differences between the coating microstructures, the micromechanical properties appear much less influenced by the flame conditions. Indentation micro-hardness values ( $\mathrm{H}_{\mathrm{IT}}$, as defined in ISO 14577-1) are all very similar to one another, as summarized in Figure 8, and range between 6.2 and 7.4 GPa. The values of nano-hardness appear to be slightly higher than those of microhardness, as commonly observed in thermal sprayed coatings [52]. The higher load applied in the micro-hardness test leads to bigger indentation marks. Thus, micro-hardness tests return an average material response, which 
includes inelastic sliding effects due to interlamellar boundaries, oxides and porosity. To the contrary, the much lower load applied in the nano-hardness test leads to indentation marks, which are usually smaller than the average dimensions of a single lamella. Thus, the nanohardness values are sensitive of the intra-lamellar properties, and are less affected by the coating defectiveness.

\subsection{Tribology of Stellite coatings}

\subsubsection{Ball-on-disk dry sliding wear test: wear rates and friction coefficients}

The values of wear rate measured after dry sliding ball-on-disk tests at room temperature $(\approx 25$ $\left.{ }^{\circ} \mathrm{C}\right), 400{ }^{\circ} \mathrm{C}$ and $800{ }^{\circ} \mathrm{C}$ are reported in Figure 9A. Despite the differences among coating microstructures, the values of wear rate are very similar to each other, which indicates the "easy applicability" of the Stellite-6 alloy as a wear resistant coating, since possible fluctuations of the thermal spray system, as well as limited changes to the spraying parameters, will not drastically affect the wear resistance, though changing the microstructure to some extent.

Wear rate values between $1.66 \times 10^{-5}$ and $3.48 \times 10^{-5} \mathrm{~mm}^{3} /(\mathrm{N} \cdot \mathrm{m})$ were measured at room temperature. They increase to $5.69 \times 10^{-5}-7.44 \times 10^{-5} \mathrm{~mm}^{3} /(\mathrm{N} \cdot \mathrm{m})$ at $400{ }^{\circ} \mathrm{C}$, but decrease from $400{ }^{\circ} \mathrm{C}$ to $800{ }^{\circ} \mathrm{C}$, attaining values between $7.14 \times 10^{-6}$ and $2.04 \times 10^{-5} \mathrm{~mm}^{3} /(\mathrm{N} \cdot \mathrm{m})$, i.e. lower than those measured at room temperature. This directly confirms the very good performances of Stellite-6 as a wear resistant coating in high-temperature conditions.

The steady-state coefficient of friction attained after a certain sliding distance, on the other hand, decreases considerably with increasing temperature, as shown in the case of sample Run1 (Figure 9B), chosen as representative of the behavior of all tested samples. The coefficients of friction measured on samples deposited with different spraying parameters are indeed very similar to each other (Figure 9C), consistently with the similar wear mechanism previously discussed. 
At room temperature, however, the coefficient of friction shows a sharp transition after a sliding distance of a few hundred meters (Figure 9B). Differently, at higher temperature the friction coefficient stabilized after a running-in period of less than $200 \mathrm{~m}$, and was maintained till the end of the test.

\subsubsection{Ball-on-disk dry sliding wear test: worn surface morphologies}

Figure 10 shows the FE-SEM micrographs of the wear tracks of coating Run6 after testing at room temperature, $400{ }^{\circ} \mathrm{C}$ and $800{ }^{\circ} \mathrm{C}$, together with some EDX spectra.

At R.T., abrasive grooves, due to hard asperities on the counterpart and/or to trapped debris particles, appear together with some pits and cracks left by the brittle detachment of lamellae from the coating, as observed in the micrographs (Figure 10A and D). Cross-sectional views (Figure 11A) confirm that brittle detachment occurs along the boundaries between splats, probably in correspondence of oxidized lamellae or partially molten/unmolten particles. Differently, in the wear scars obtained at $400{ }^{\circ} \mathrm{C}$, no signs of brittle cracking or lamellae delamination can be observed (Figure 10B and E). Wear proceeds by abrasive grooving of the surface, with larger, deeper grooves than at room temperature (compare Figure 10E to Figure 10D), consistent with the higher overall wear rate, and a minor component of adhesive wear. This is also corroborated by the optical micrographs of the $\mathrm{Al}_{2} \mathrm{O}_{3}$ counterparts used against sample Run6 at RT and $400{ }^{\circ} \mathrm{C}$ (Figure 12A and B, respectively), which show a different morphology despite the very similar measured wear rates. Bright spots of plastically deformed metal due to adhesive wear and material transfer are clearly visible after wear at $400{ }^{\circ} \mathrm{C}$ (Figure 12B), together with darker areas, presumably consisting of oxidized debris.

Differently, after wear at RT, dark clusters of oxidized wear debris are spread onto the mildly abraded surface of the sphere, but no signs of direct transfer of metallic material are visible (Figure 12A). 
These observations therefore point out to the occurrence of tribo-oxidation as an additional wear mechanism. Clusters of oxidized debris are indeed found on the worn coating surfaces as well, both at RT (SEM micrograph in Figure 10G and EDX spectra 2 and 3 in Figure 10J) and at $400{ }^{\circ} \mathrm{C}$ (SEM micrograph in Figure $10 \mathrm{H}$ and EDX spectrum 5 in Figure 10K). At low magnification, a higher amount of oxidized spots can be seen in the high temperature-tested sample (compare Figure 10B to Figure 10A). In both cases, they can be identified through their broad Raman peaks (Figure 13) as consisting mainly of $\mathrm{CoO}[53,54]$, with a minor peak at $194 \mathrm{~cm}^{-1}$ belonging to $\mathrm{Co}_{3} \mathrm{O}_{4}[55]$ and/or $\mathrm{CoCr}_{2} \mathrm{O}_{4}$ [56]; therefore, they probably consist of oxidized metal fragments. The low Al content revealed by the EDX spectra (Figure 10J and $\mathrm{K}$ ) is explained by the limited wear loss of the counterbody (Figure 9A). However, morphologies differ significantly. At room temperature, oxidized areas look like patches with limited adherence to the worn coating surface (Figure 10D and G). Sometimes, they fill in the delamination pits. They are not visible in the cross-sectional micrograph of Figure 11A, suggesting that either they are not very widespread, or they are easily pulled out during polishing due to poor adhesion to the underlying metal. Differently, at $400{ }^{\circ} \mathrm{C}$ the oxidized clusters seem to be more strongly bound to the underlying metal surface, forming a discontinuous tribolayer (Figure 10H) also visible in the cross sectional micrograph of Figure 11B. The oxide layer, which appears as a dark gray film on the surface of the $400{ }^{\circ} \mathrm{C}$-tested samples, is mixed with light gray stripes of non-oxidized alloy, as highlighted with dark arrows (Figure 11B). This finding is consistent with the previously mentioned presence of metal on the counterbody surface, and it probably contributes to explaining the compactness of the clusters, as residual metal likely increases their toughness.

Worn surface morphologies change remarkably at $800{ }^{\circ} \mathrm{C}$. At this temperature, the wear track (Figure 10C,F) is uniformly covered by a continuous and rather smooth tribofilm (a "glaze" 
film). In cross-sectional views (Figure 14A-D), it appears much thicker than the clusters formed at $400{ }^{\circ} \mathrm{C}$ (Figure 12), quite dense, and strongly bonded to the underlying metal. Further, the surface of the alloy, outside the wear track, oxidized spontaneously into a scale which, according to Raman spectra, is based on $\mathrm{Cr}_{2} \mathrm{O}_{3}$ [57] with minor amounts of $\mathrm{Co}_{3} \mathrm{O}_{4}$ and/or $\mathrm{CoCr}_{2} \mathrm{O}_{4}[55,56]$ (Figure 13). This composition is consistent with a previous report by Shoja-Razavi [26]. The scale is clearly visible in the micrograph of Figure 10I, which is a portion of the coating surface outside the wear trace, and in the cross-sectional view of Figure $14 \mathrm{E}$.

The detail in Figure 14B specifically shows that the tribofilm comprises an outer, thicker layer (label 1) of compacted wear debris particles, which are barely identifiable, but still recognizable in magnified views (Figure 14C), and an underlying layer (label 2) that morphologically resembles (see the detail in Figure 14D) the spontaneous oxide scale outside the wear track (Figure 14E). The interface between the top layer and the underlayer seems to be free of defects (Figure 14E), and it is possible that local sintering or chemical interactions occurred.

The composition of the outer layer differs from that of the spontaneous scale formed outside the wear track, as it consists primarily of $\mathrm{Co}_{3} \mathrm{O}_{4}$ and/or $\mathrm{CoCr}_{2} \mathrm{O}_{4}$, with smaller amounts of $\mathrm{Cr}_{2} \mathrm{O}_{3}$ (Figure 13).

\subsubsection{Dry sand-steel wheel abrasion testing}

The wear rates measured with the dry sand-steel wheel test on the coatings deposited with different spraying parameters are reported in Figure 15. Analogously to the dry sliding wear test, all the coatings show similar abrasion wear resistance, despite the differences in their microstructures. Wear rates $\approx 10^{-3} \mathrm{~mm}^{3} /(\mathrm{N} \cdot \mathrm{m})$ are comparable to those reported by other authors under rubber-wheel test conditions using a similar $\mathrm{Al}_{2} \mathrm{O}_{3}$ abrasive [23,24]. The wear mechanisms (Figure 16) consist of strong abrasive grooving, with plastic deformation of the 
alloy, and of indentation by the $\mathrm{Al}_{2} \mathrm{O}_{3}$ sand. A deep indentation mark is seen in Figure 16, in the area marked as "spectrum 2". Indenting particles are sometimes implanted into the alloy as a result of this process, as shown by the backscattered electron micrograph in Figure 16B and the corresponding EDX spectra 3 and 4 in Figure 16C.

\subsubsection{Analysis and interpretation of wear mechanisms}

The ball-on-disk dry sliding wear rates measured at room temperature are consistent with previous reports on other HVOF-sprayed coatings [23,25,58], but they are one order of magnitude higher than the wear rate inferable from the volume loss data reported for PTAcladded Stellite under very similar ball-on-disk test conditions ( 6 mm-diameter $\mathrm{Al}_{2} \mathrm{O}_{3}$ ball, 3 $\mathrm{N}$ load, $500 \mathrm{~m}$ distance, $0.1 \mathrm{~m} / \mathrm{s}$ sliding speed). The latter is indeed $\approx 4 \times 10^{-6} \mathrm{~mm}^{3} /(\mathrm{N} \cdot \mathrm{m})$ [9], and analogous wear rates of $4 \div 6 \times 10^{-6} \mathrm{~mm}^{3} /(\mathrm{N} \cdot \mathrm{m})$ can also be obtained from data for bulk (cast or hot isostatically pressed) Stellite under reciprocating ball-on-disk conditions against a WC-Co counterpart [5], and under block-on-ring conditions against a carburized steel counterpart at $\approx 133 \mathrm{~N}$ load [13].

No reference data for bulk Stellite under the high-stress steel wheel abrasion test could be found; however, it is noted that, after an ASTM G65 rubber wheel abrasion test performed using silica sand as abrasive, the wear rates of Stellite coatings deposited by a gas-fueled HVOF spraying process $\left(7.0-8.0 \times 10^{-4} \mathrm{~mm}^{3} /(\mathrm{N} \cdot \mathrm{m})[59]\right)$ are not much lower than those shown in Figure 15 and Section 3.3.3. The wear rates of bulk Stellite in the ASTM G65 test, by contrast, are $1-5 \times 10^{-5} \mathrm{~mm}^{3} /(\mathrm{N} \cdot \mathrm{m})$, as computed from volume loss data in [3-5], i.e. they are lower by one to two orders of magnitude.

The poorer wear resistance of HVOF-sprayed Stellite in comparison to bulk and clad ones at room temperature is explained by the presence of lamellar boundaries acting as the weak link within the material. They induce delamination and pit formation under sliding wear conditions (Section 3.3.2, Figure 10A,D,G, and Figure 11A); analogously, during the steel- 
wheel test, indentation by the abrasive (as described in Section 3.3.3) is presumably facilitated by the dislodgement of poorly bonded, unmolten particles. Moreover, in the HVOF-sprayed coatings, no carbide phases are present (Section 3.2) to support the contact load during sliding or abrasive wear processes, unlike bulk and clad Stellites, as recalled in the Introduction [4,5]. On the other hand, the HVOF-sprayed coatings are capable of the same, strain-induced f.c.c. $\rightarrow$ h.c.p. "martensitic" phase transformation, which is well documented for bulk Stellite (as summarised in the Introduction). Bright field (BF) TEM images and selected area electron diffraction (SAED) patterns acquired inside the wear track indeed reveal a 1-2 $\mu$ m thick subsurface layer with mainly Co-based h.c.p. structure (Figure 17). Analogous surface layers are formed, under sliding wear conditions, in clad Stellites [2,11]; however, up until now, no direct observation of transformed layers in thermal spray Stellite coatings was available. The occurrence of the f.c.c. $\rightarrow$ h.c.p. transition on the worn surfaces of HVOF- and cold-sprayed Stellite-6 has only been documented through X-ray diffraction in recent studies by Houdková et al. [25] and by Cinca et al. [59]. Below the transformed layer, a fine-grained f.c.c. structure (Figure 17) is found. Outside the wear track (Figure 18), the same f.c.c. structure can be seen extending up to the polished surface, indicating that no mechanically altered layer was left at the end of the polising procedure described in Section 2.2.

The f.c.c. $\rightarrow$ h.c.p. transition hardens the surface layer within the contact region, as previously shown by the authors through nano-indentation tests performed inside the ball-on-disk wear track of an analogous HVOF-sprayed Stellite-6 coating [58]. Due to its hardness, the surface layer has little tendency to adhere to the counterbody, as noted in Section 3.3.2; therefore, the friction coefficient initially produced by the HVOF-sprayed coatings during the sliding wear test at room temperature (Figure 9B,C) is somewhat lower than it has been found for other metallic coatings tested under identical conditions, including Fe-based alloys $[60,38]$ and electroplated hard chromium [60]. 
The subsequent, sharp transition from a lower-friction regime to a higher-friction one, occurring after a sliding distance of a few hundred meters (Figure 9B), has also been reported for HVOF-sprayed Stellite-6 by Houdková et al. [24,25], although absolute values of the friction coefficient were different from the present ones, since the cited works employed $100 \mathrm{Cr} 6$ [24] or AISI 440C [25] spherical counterbodies instead of $\mathrm{Al}_{2} \mathrm{O}_{3}$. The wear trace produced in a room-temperature ball-on-disk test stopped after a distance of $100 \mathrm{~m}$ (i.e. before the friction transition) is almost free from oxidized wear debris (Figure 19), unlike the wear scars seen after $2500 \mathrm{~m}$ (Figure 10A,D,G). A very thin layer of darker oxides is only visible in the magnified micrograph of Figure 19B. Indeed, due to the high intrinsic oxidation resistance of the Stellite-6 alloy (see the DTA/TG results in Section 3.1), a substantial amount of heat has to be dissipated by friction before wear debris starts reacting significantly with surrounding air. Once this occurs, clusters of oxidized debris build up onto both the coating and the counterbody: they are clearly responsible for increasing the friction coefficient. Accordingly, the wavy morphology of the clusters (Figure 10D,G) shows they are subjected to high tangential forces. Probably, adsorption of humidity from the environment increases the interaction forces between oxide clusters adhering to the mating surfaces.

No data on the high-temperature dry sliding wear resistance of HVOF-sprayed Stellite is available. The overall trend described in Section 3.3.1 and Figure 9A matches with that of bulk and cladded Stellite alloys (sumarized in the Introduction); however, it is remarkable that, at $400{ }^{\circ} \mathrm{C}$, the wear rate of the present HVOF-sprayed samples becomes even lower than that of PTA stellite, reportedly $\approx 2.5 \times 10^{-4} \mathrm{~mm}^{3} /(\mathrm{N} \cdot \mathrm{m})$ (as computed from volume loss data in [9]).

As shown in Section 3.3.2, lamellar delamination is suppressed, which is likely a consequence of thermal softening: as the hardness of the metallic phases in Stellite alloys decreases linearly with temperature [16], the brittleness of the system is conceivably lessened as well. If lamellar 
boundaries play no role, the coatings behave similar to a bulk material. Just like bulk or clad Stellites $[9,10]$, the coatings suffer more severe grooving and develop a significant transfer layer on the counterbody due to an adhesive wear component. Since the HVOF-sprayed coatings retained, even at $400{ }^{\circ} \mathrm{C}$ (Figure 11B), their very fine-grained structure (previously described Section 3.2), they possess a slight advantage in resisting abrasion, as compared to bulk or clad materials with much coarser microstructure.

On the other hand, at $400{ }^{\circ} \mathrm{C}$ the coatings are incapable of developing a continuous oxide tribolayer convering the whole surface, which agrees with the behavior of bulk Stellite- 6 according to Wood et al. [8], though the formation of a "glaze" layer at this temperature was reported for PTA-cladded Stellite-12 [9]. Outside the wear track, the HVOF-sprayed Stellite-6 coating spontaneously develops a very thin oxide scale, hardly visible by microscopy techniques, but detectable by Raman spectroscopy (Figure 13). The latter reveals the scale to be based on $\mathrm{Co}_{3} \mathrm{O}_{4}$ and/or $\mathrm{CoCr}_{2} \mathrm{O}_{4}$ (Figure 13). However, the TG-DTA test (Figure 3) suggests that its growth rate is very low, and the presence of oxide-free areas inside the wear tracks (Figure 10H,K: EDX spectrum 4) confirms that the coating wears faster than the layer is formed; hence, the spontaneous oxide scale plays no role in the wear process, analogous to the behavior of PTA-cladded Stellite- 1 between $300{ }^{\circ} \mathrm{C}$ and $500{ }^{\circ} \mathrm{C}$ [17]. Even the additional temperature peak, which the flash heating phenomenon produces in the contact point, cannot reverse this situation. The flash temperature rise $\Delta T_{f}$ can be estimated through the equation (2) proposed by Ashby et al. [61]:

$$
\Delta T_{f}=\left(\frac{\mu F v}{A_{r}}\right) /\left(\frac{k_{1}}{l_{f 1}}+\frac{k_{2}}{l_{f 2}}\right)
$$

Where:

$A_{r}=A_{n}\left(F / F_{S}\right)=$ real contact area between the mating bodies; $A_{n}=$ nominal contact area; $F$ $=$ applied normal force; $F_{S}=\left(A_{n} H\right) / \sqrt{1+12 \mu^{2}}=$ seizure force; $H=$ hardness of the softer 
mating body $k_{1}, k_{2}=$ thermal conductivities of the mating bodies; $l_{f 1}, l_{f 2}=$ heat diffusion lengths for flash heating on the mating surfaces.

Based on Figure 12B, the nominal contact area is $A_{n} \approx 0.5 \mathrm{~mm}^{2}$ after the ball and the coating surface have conformed through initial wear; the thermal conductivity of $\mathrm{Al}_{2} \mathrm{O}_{3}$ is taken as $k_{1} \approx 18.9 \mathrm{~W} /(\mathrm{m} \cdot \mathrm{K})$ from [62] and $k_{2} \approx 9 \mathrm{~W} /(\mathrm{m} \cdot \mathrm{K})$ is assumed for HVOF-sprayed Stellite, by analogy with the thermal conductivity of thermal spray stainless steel [63]; $\mu \approx 0.65$ (Figure 9C); $H \approx 7$ GPa (Figure 8). Following the simplification proposed by Straffelini [64], the heat diffusion lengths are assumed to be equal to the junction radius $r_{j}$, in turn estimated as $r_{j} \approx 0.01 / H_{V} \approx 15 \mu \mathrm{m}$.

As a result, from equation (2) it is found that $\Delta T_{f} \approx 280{ }^{\circ} \mathrm{C}$, which suggests a maximum contact point temperature of approximately $680{ }^{\circ} \mathrm{C}$, i.e. below the $\approx 750{ }^{\circ} \mathrm{C}$ threshold for fast oxidation of the alloy (Section 3.1). The oxide scale on the coating surface therefore grows too slowly to be reformed during the wear test.

Nevertheless, because of the higher environmental temperature, the wear debris starts oxidizing immediately after the beginning of the test, which means no transition between lower- and higher-friction regimes takes place (Figure 9B), unlike it happened at room temperature. Notably, the average friction coefficient is lower at $400{ }^{\circ} \mathrm{C}$ than it is at RT after the transition (Figure 9B,C). This might seem unexpected, because the composition of the oxide clusters is the same (Section 3.3.2 and Figure 13), and because the presence of metal fragments in the clusters and on the counterbody (Section 3.3.2, Figure 11B and Figure 12B respectively) might have even led to seizure between the mating bodies. In accordance with previous considerations, lower friction can be ascribed to the absence of adsorbed moisture within the clusters at high temperature.

At $800{ }^{\circ} \mathrm{C}$, the wear rates of the HVOF-sprayed coatings are comparable to or lower than those recorded, at $700{ }^{\circ} \mathrm{C}$, for PTA-cladded Stellite-12 $\left(\approx 3 \times 10^{-5} \mathrm{~mm}^{3} /(\mathrm{N} \cdot \mathrm{m})\right.$, again inferred 
from volume loss data in [9]) and Stellite-1 $\left(\approx 2 \times 10^{-4} \mathrm{~mm}^{3} /(\mathrm{N} \cdot \mathrm{m})\right.$ [17]). The wear mechanism consists of the dynamic growth and removal (by abrasion and fatigue-induced delamination) of the thick "glaze" tribofilm described in Section 3.3.2. The presence of compacted particles (Section 3.3.2) indicates that the "glaze" forms by smearing and sintering of oxidized debris onto the coating surface. In Figure 14B, label 3 indicates a location where the tribofilm is being reformed after a delamination event: debris particles have not been completely sintered yet, but they are being compacted on the outer surface. Smearing and sintering is clearly promoted by the high test temperature and by the additional contribution of flash heating. Moreover, some metallic debris can be embedded in the tribolayer (Figure 14A - see arrows): as its oxidation progresses, it bonds to the surrounding particles, further contributing to the overall densification. Likewise, oxidation of the underlying metal surface, occurring at a higher rate than it happened at $400{ }^{\circ} \mathrm{C}$, enhances the adhesion and stability of the "glaze", as noted in Section 3.3.2. This is probably a key factor to explain why an adherent, continuous "glaze" could develop at $800{ }^{\circ} \mathrm{C}$ but not at $400{ }^{\circ} \mathrm{C}$.

Since the "glaze" comes from complete oxidation of alloy fragments, it consists primarily of $\mathrm{Co}_{3} \mathrm{O}_{4}$ and/or $\mathrm{CoCr}_{2} \mathrm{O}_{4}$, with smaller amounts of $\mathrm{Cr}_{2} \mathrm{O}_{3}$ (Figure 13), unlike the $\mathrm{Cr}_{2} \mathrm{O}_{3}$-richer spontaneous scale outside the wear track. Raman peaks of the "glaze" are also broader, because of plastic deformation during contact, and systematically shifted, because of the incorporation of other alloy elements, such as W, Fe, Ni (Section 2.1).

These results confirm the previous hypothesis by Wood et al. on "glaze" formation by sintering of debris on bulk Stellite [8], clarifying the exact mechanisms of this process and extending this concept to HVOF-sprayed coatings as well.

\subsubsection{Corrosion behavior of Stellite coatings}

Different from the tribological properties, the corrosion resistance of the Co-based alloy coatings is more significantly influenced by the coating microstructure, hence by the 
deposition parameters. The highest $\mathrm{I}_{\text {corr }}$ and lowest (highest in modulus) $\mathrm{E}_{\text {corr }}$ values were indeed measured on porous samples Run4 and Run5, whilst the values of $\mathrm{I}_{\text {corr }}$ measured on the dense ( $<1 \%$ porosity) coatings are lower and close to each other (Figure 20$)$.

The polarization curves of dense coatings such as Run6 (Figure 21) also show a phenomenon of pseudo-passivation: the current density remains constant (or decreases a bit) over a large range of anodic overpotentials. Only a small part of the analyzed potential range, exceeding $+0.9 \mathrm{~V}$, leads to transpassivation of the alloy. Pseudo-passivation indicates the formation of a quite stable layer of protective species (probably based on chromium oxide), which acts as a barrier against further corrosion.

Accordingly, the cross section of dense samples appears almost unaltered (Figure 22B). Running the polarization test above the transpassivation threshold was not enough to induce visible damages to the coating. The corrosive solution was able to reach the substrate at some points, and few corrosion products can be observed at the interface; however, a Corrodkote test performed on the samples with the lowest porosity (Run1 and Run3) proves their good long-term corrosion resistance. They could indeed survive 100 hours of corrosion testing almost unaltered (Figure 23), a feature that can be achieved only by the densest and most protective thermal-spray coatings $[65,66]$. No signs of red corrosion products from the substrate, nor swelling or deformation of the coating can be observed. Only some residuals of kaolin from the corrosive suspension, very well bonded to the surface, can be observed after each cycle, which may indicate that some pits formed on the coating, to which kaolin could attach.

In highly porous samples such as Run5, by contrast, corrosive agents penetrated massively down to the substrate. Since little oxygen is present at the interface, the stainless steel substrate is not able to passivate and is preferentially corroded, acting as an anode with respect to the nobler Co-based alloy (Figure 22A). Fe-based corrosion products accumulated at the coating-substrate interface, causing an evident swelling of the coating and its eventual 
delamination. No real passivation can indeed be observed in the polarization curves of these samples, as suggested by the current density fluctuations with increasing potential (Figure 21).

\section{Conclusions}

HVOF-sprayed Stellite- 6 coatings were obtained by systematic variation of the deposition parameters (powder feed rate, oxygen and hydrogen flow rates). The characterization of their microstructure, phase composition, hardness, corrosion resistance, sliding and abrasive wear performance has led to the following conclusions:

- The microstructure and phase composition of the coatings depend on the fuel/oxygen equivalence ratio. A fuel-rich gas mixture produces dense coatings (porosity <1\%) comprising a significant fraction of molten, flattened lamellae. Impact-quenching suppresses the precipitation of $\mathrm{Cr}_{7} \mathrm{C}_{3}$-based carbides, thus resulting in the formation of a Cr-enriched phase with f.c.c. structure, characterized by a slightly larger lattice parameter in comparison to the equilibrium, Co-based solid solution. Rietveld refinement of XRD patterns confirms that the mass fraction of the Cr-enriched phase increases linearly with decreasing equivalence ratio, corresponding with the increase in the content of molten lamellae.

- The microstructure plays a major effect on the corrosion resistance of coated systems. Coatings with $<1 \%$ porosity exhibit pseudo-passive behavior and protect the substrate effectively, which allows the coated system to survive 5 cycles $(100 \mathrm{~h})$ of the Corrodkote test (ASTM B380-97) without any obvious sign of substrate corrosion.

- On the other hand, the wear behavior is less influenced by microstructure. In sliding wear at room temperature, all coatings exhibit wear rates of $2 \div 3 \times 10^{-5} \mathrm{~mm}^{3} /(\mathrm{N} \cdot \mathrm{m})$ with signs of mild abrasion and pitting due interlamellar delamination. A strain-induced, f.c.c. $\rightarrow$ h.c.p. "martensitic" phase transformation occurs over a depth of $1-2 \mu \mathrm{m}$ below the contact surface. The hardened surface layer initially maintains the friction coefficient 
down to $\approx 0.6$. After a sliding distance of few hundred meters, frictional heating raises the temperature of the debris trapped in the contact area and causes tribo-oxidation. At this point, high tangential forces acting between oxidized debris clusters attached to the mating surfaces cause a significant increase in friction coefficient (from $\approx 0.65$ to $\approx 0.8$ ). In highstress dry particle abrasion, severe grooving and indentation by abrasive particles result in wear rates of $9 \times 10^{-4} \div 1 \times 10^{-3} \mathrm{~mm}^{3} /(\mathrm{N} \cdot \mathrm{m})$.

- At $400{ }^{\circ} \mathrm{C}$, lamellar delamination is suppressed; hence, the dry sliding wear performance of the coatings is at least comparable to that of bulk or clad Stellite. Nonetheless, an overall increase of the wear rates up to $5 \div 8 \times 10^{-5} \mathrm{~mm}^{3 /}(\mathrm{N} \cdot \mathrm{m})$ is caused by more severe abrasive wear and by additional adhesive wear. The friction coefficient, on the other hand, decreases to $\approx 0.65$, although tribo-oxidized clusters become more widespread: probably, the interlocking between oxidized clusters attached to the mating bodies is lessened by the absence of adsorbed humidity at this temperature.

- At $800{ }^{\circ} \mathrm{C}$, the wear scar is entirely covered by a smooth, dense tribofilm (a "glaze"), consisting of sintered debris particles strongly bound to an underlying layer of "native" oxide formed on the metal surface. This tribofilm protects the coating, lowering the wear rate to $\approx 1 \times 10^{-5} \mathrm{~mm}^{3 /}(\mathrm{N} \cdot \mathrm{m})$ and the friction coefficient to $<0.45$. Wear proceeds through its dynamic removal (by fracturing and delamination) and re-constitution (by further attachment and sintering of debris).

- It is eventually inferred that strict control over process parameters is required when the coatings operate in corrosive environments, whilst wear-dominated conditions are more forgiving in this respect.

\section{Acknowledgements}

The authors are grateful to Dr. Paola Miselli (University of Modena and Reggio Emilia) for performing DTA/TG tests. 
Bibliography

[1] J.R. Davis, ASM Specialty Handbook: Nickel, Cobalt, and Their Alloys, ASM International, Materals Park, OH, USA.

[2] D.H.E. Persson, On the Mechanisms behind the Tribological Performance of Stellites, Uppsala University, 2005.

http://www.diva-portal.org/smash/get/diva2:167455/FULLTEXT01.pdf.

[3] W.S. Da Silva, R.M. Souza, J.D.B. Mello, H. Goldenstein, Room temperature mechanical properties and tribology of NICRALC and Stellite casting alloys, Wear 271 (2011) 1819-1827.

[4] H. Yu, R. Ahmed, H. de Villiers Lovelock, S. Davies, Influence of Manufacturing Process and Alloying Element Content on the Tribomechanical Properties of CobaltBased Alloys, J. Tribol. 131 (2009) 11601.

[5] H. Yu, R. Ahmed, H. de Villiers Lovelock, A Comparison of the Tribo-Mechanical Properties of a Wear Resistant Cobalt-Based Alloy Produced by Different Manufacturing Processes, J. Tribol. 129 (2007) 586.

[6] M. Sebastiani, V. Mangione, D. De Felicis, E. Bemporad, F. Carassiti, Wear mechanisms and in-service surface modifications of a Stellite 6B Co-Cr alloy, Wear 290-291 (2012) $10-17$.

[7] A. Frenk, W. Kurz, Microstructural effects on the sliding wear resistance of a cobaltbased alloy, Wear 174 (1994) 81-91.

[8] P.D. Wood, H.E. Evans, C.B. Ponton, Investigation into the wear films formed on certain superalloys between 20 and $600^{\circ} \mathrm{C}$ during rotation in an unlubricated bearing, in: Proc. ASME/STLE 2009 Int. Jt. Tribol. Conf., Memphis, Tennessee, USA, 2009: pp. 91-93.

[9] A. Motallebzadeh, E. Atar, H. Cimenoglu, Raman spectroscopy characterization of hypo-eutectic CoCrWC alloy tribolayers, Ind. Lubr. Tribol. 68 (2016) 515-520.

[10] M.C. Jeng, L.Y. Yan, J.L. Doong, Wear behaviour of cobalt-based alloys in laser surface cladding, Surf. Coatings Technol. 48 (1991) 225-231.

[11] D.H.E. Persson, E. Coronel, S. Jacobson, S. Hogmark, Surface analysis of laser cladded Stellite exposed to self-mated high load dry sliding, Wear 261 (2006) 96-100.

[12] J.F. Lin, Y.N. Chen, Tribological reaction generated on ceramic-stellite couples under dry sliding contact and water- and oil-lubricated conditions, Wear 177 (1994) 139-149.

[13] K.J. Bhansali, A.E. Miller, The role of stacking fault energy on galling and wear behavior, Wear 75 (1982) 241-252.

[14] L.Y. Tian, R. Lizárraga, H. Larsson, E. Holmström, L. Vitos, A first principles study of 
the stacking fault energies for fcc Co-based binary alloys, Acta Mater. 136 (2017) 215223.

[15] D.H.E. Persson, S. Jacobson, S. Hogmark, Antigalling and low friction properties of a laser processed Co-based material, J. Laser Appl. 15 (2003) 115-119.

[16] S. Kapoor, R. Liu, X.J. Wu, M.X. Yao, Temperature-Dependence of Hardness and Wear Resistance of Stellite Alloys, World Acad. Sci. Eng. Technol. 67 (2012) 964-973.

[17] L. da Conceição, A.S.C.M. D'Oliveira, The effect of oxidation on the tribolayer and sliding wear of a Co-based coating, Surf. Coatings Technol. 288 (2016) 69-78.

[18] D. Lee, Wear-Resistant Coatings, in: R.C. Tucker Jr. (Ed.), ASM Handb. Vol. 5A Therm. Spray Technol., ASM International, Materals Park, OH, USA, 2013: pp. 253-256.

[19] A. Kumar, J. Boy, R. Zatorski, L.D. Stephenson, Thermal Spray and Weld Repair Alloys for the Repair of Cavitation Damage in Turbines and Pumps: A Technical Note, J. Therm. Spray Technol. 14 (2005) 177-182.

[20] G. Kong, D. Zhang, P.D. Brown, D.G. McCartney, S.J. Harris, Microstructural characterisation of high velocity oxyfuel thermally sprayed Stellite 6, Mater. Sci. Technol. 19 (2003) 1003-1011.

[21] A. Kusmoko, D. Dunne, H. Li, A Comparative Study for Wear Resistant of Stellite 6 Coatings on Nickel Alloy Substrate Produced by Laser Cladding, HVOF and Plasma Spraying Techniques, Int. J. Curr. Eng. Technol. 4 (2014) 32-36.

[22] Š. Houdková, M. Kašparová, J. Schubert, The Spraying Parameters Optimization of the HVOF Stellite 6 Coating, in: 21st Int. Conf. Metall. Mater., Brno, Czech Republic, 2012.

[23] Š. Houdková, E. Smazalová, The Influence of High Temperature Exposure on the Wear of Selected HVOF Sprayed Coatings, Defect Diffus. Forum 368 (2016) 55-58.

[24] S. Houdkova, E. Smazalova, Z.Z. Pala, Š. Houdková, E. Smazalová, Z.Z. Pala, Effect of Heat Treatment on the Microstructure and Properties of HVOF-Sprayed Co-Cr-W Coating, J. Therm. Spray Technol. 25 (2016) 546-557.

[25] Š. Houdková, Z. Pala, E. Smazalová, M. Vostřák, Z. Česánek, Microstructure and sliding wear properties of HVOF sprayed, laser remelted and laser clad Stellite 6 coatings, Surf. Coatings Technol. 318 (2017) 129-141.

[26] R. Shoja-Razavi, Laser Surface Treatment of Stellite 6 Coating Deposited by HVOF on 316L Alloy, J. Mater. Eng. Perform. 25 (2016) 2583-2595.

[27] C.R. Ciubotariu, D. Frunzăverde, G. Mărginean, V.A. Şerban, A.V. Bîrdeanu, Optimization of the laser remelting process for HVOF-sprayed Stellite 6 wear resistant coatings, Opt. Laser Technol. 77 (2016) 98-103.

[28] H.S. Sidhu, B.S. Sidhu, S. Prakash, Performance of HVOF sprayed NiCr and Stellite-6 
coatings under Pin on Disc wear testing, Mater. Sci. Forum 701 (2012) 21-29.

[29] H.S. Sidhu, B.S. Sidhu, S. Prakash, Solid particle erosion of HVOF sprayed NiCr and Stellite-6 coatings, Surf. Coatings Technol. 202 (2007) 232-238.

[30] T.S. Sidhu, S. Prakash, R.D. Agrawal, Studies of the metallurgical and mechanical properties of high velocity oxy-fuel sprayed stellite-6 coatings on $\mathrm{Ni}$ - and Fe-based superalloys, Surf. Coatings Technol. 201 (2006) 273-281.

[31] M.K. Stanford, V.K. Jain, Friction and wear characteristics of hard coatings, Wear 250251 (2001) 990-996.

[32] T.S. Sidhu, S. Prakash, R.D. Agrawal, Hot corrosion studies of HVOF NiCrBSi and Stellite-6 coatings on a Ni-based superalloy in an actual industrial environment of a coal fired boiler, Surf. Coatings Technol. 201 (2006) 1602-1612.

[33] B.S. Sidhu, S. Prakash, Studies on the behaviour of stellite-6 as plasma sprayed and laser remelted coatings in molten salt environment at $900{ }^{\circ} \mathrm{C}$ under cyclic conditions, J. Mater. Process. Technol. 172 (2006) 52-63.

[34] T.S. Sidhu, S. Prakash, R.D. Agrawal, Hot Corrosion Resistance of High-Velocity Oxyfuel Sprayed Coatings on a Nickel-Base Superalloy in Molten Salt Environment, J. Therm. Spray Technol. 15 (2006) 387-399.

[35] Z. Pala, M. Bai, F. Lukac, T. Hussain, Laser Clad and HVOF-Sprayed Stellite 6 Coating in Chlorine-Rich Environment with $\mathrm{KCl}$ at 700 \{ Itextdegree\}C, Oxid. Met. 88 (2017) $749-771$.

[36] A.C. Larson, R.B. Von Dreele, General Structure Analysis System (GSAS), 1994.

[37] B.H. Toby, EXPGUI, a graphical user interface for GSAS, J. Appl. Crystallogr. 34 (2001) 210-213.

[38] G. Bolelli, M. Bursi, L. Lusvarghi, T. Manfredini, V. Matikainen, R. Rigon, P. Sassatelli, P. Vuoristo, Tribology of FeVCrC coatings deposited by HVOF and HVAF thermal spray processes, Wear 394-395 (2018) 113-133.

[39] G. Bolelli, A. Candeli, L. Lusvarghi, T. Manfredini, A. Denoirjean, S. Valette, A. Ravaux, E. Meillot, "Hybrid" plasma spraying of NiCrAlY+Al2O3+h-BN composite coatings for sliding wear applications, Wear 378-379 (2017) 68-81.

[40] F. Mansfeld, Electrochemical Methods of Corrosion Testing, in: S.D. Cramer, B.S. Covino Jr. (Eds.), Corros. Fundam. Testing, Prot. - ASM Handb. Vol. 13A, ASM International, Materials Park, OH, USA, 2003: pp. 446-462.

[41] E. McCafferty, Validation of corrosion rates measured by the Tafel extrapolation method, Corros. Sci. 47 (2005) 3202-3215.

[42] U.O.B. de Oliveira, Laser treatment of alloys: processing, microstructure and structural 
properties, University of Groningen, 2007.

https://www.rug.nl/research/portal/files/2771221/titlecon.pdf.

[43] F. Duflos, J.F. Stohr, Comparison of the quench rates attained in gas-atomized powders and melt-spun ribbons of $\mathrm{Co}$ - and Ni-base superalloys: influence on resulting microstructures, J. Mater. Sci. 17 (1982) 3641-3652.

[44] L. Pawłowski, L. Pawlowski, The Science and Engineering of Thermal Spray Coatings, 2nd ed., John Wiley \& Sons Ltd., Chichester, UK, 2008.

[45] J. Koutský, High velocity oxy-fuel spraying, J. Mater. Process. Technol. 157-158 (2004) 557-560.

[46] M. Jadidi, S. Moghtadernejad, A. Dolatabadi, A comprehensive review on fluid dynamics and transport of suspension/liquid droplets and particles in High-Velocity Oxygen-Fuel (HVOF) thermal spray, Coatings 5 (2015) 576-645.

[47] P.L. Fauchais, J.V.R.R. Heberlein, M.I. Boulos, Thermal spray fundamentals: From powder to part, Springer US, New York, NY, USA, 2014.

[48] F. Gärtner, H. Kreye, H.J. Richter, HVOF Spraying with powder and wire, in: D. Böhme, P. Heinrich, J.-M. Willke, H. Kreye (Eds.), 7. Kolloquium HVOF - Conf. Proc., Gemeinschaft Thermisches Spritzen e.V., Unterschleißheim, Germany, 2006: pp. 39-56.

[49] J.R. Davis, Coating Structures, Properties, and Materials, in: Handb. Therm. Spray Technol., 2004: pp. 47-53.

[50] G. Bolelli, V. Cannillo, L. Lusvarghi, M. Montorsi, F. Pighetti Mantini, M. Barletta, F.P. Mantini, M. Barletta, Microstructural and tribological comparison of HVOF-sprayed and post-treated M-Mo-Cr-Si (M = Co, Ni) alloy coatings, Wear 263 (2007) 1397-1416.

[51] S. Deshpande, S. Sampath, H. Zhang, Mechanisms of oxidation and its role in microstructural evolution of metallic thermal spray coatings - Case study for Ni-Al, Surf. Coatings Technol. 200 (2006) 5395-5406.

[52] J. Nohava, B. Bonferroni, G. Bolelli, L. Lusvarghi, Interesting aspects of indentation and scratch methods for characterization of thermally-sprayed coatings, Surf. Coatings Technol. 205 (2010) 1127-1131.

[53] B. Rivas-Murias, V. Salgueiriño, Thermodynamic CoO-Co3O4 crossover using Raman spectroscopy in magnetic octahedron-shaped nanocrystals, J. Raman Spectrosc. (2017) 837-841.

[54] A.V. Ravindra, B.C. Behera, P. Padhan, O.I. Lebedev, W. Prellier, Tailoring of crystal phase and Néel temperature of cobalt monoxides nanocrystals with synthetic approach conditions, J. Appl. Phys. 116 (2014) 1-6.

[55] J. Park, X. Shen, G. Wang, Solvothermal synthesis and gas-sensing performance of 
$\mathrm{Co}_{3} \mathrm{O}_{4}$ hollow nanospheres, Sensors Actuators, B Chem. 136 (2009) 494-498.

[56] M. Mạczka, M. Ptak, M. Kurnatowska, J. Hanuza, Synthesis, phonon and optical properties of nanosized $\mathrm{CoCr}_{2} \mathrm{O}_{4}$, Mater. Chem. Phys. 138 (2013) 682-688.

[57] S.-H. Shim, T. Duffy, R. Jeanloz, C.-S. Yoo, V. Iota, Raman spectroscopy and x-ray diffraction of phase transitions in $\mathrm{Cr}_{2} \mathrm{O}_{3}$ to $61 \mathrm{GPa}$, Phys. Rev. B 69 (2004) 144107.

[58] P. Sassatelli, G. Bolelli, L. Lusvarghi, T. Manfredini, R. Rigon, Manufacturing and Properties of High-Velocity Oxygen Fuel (HVOF)-Sprayed FeVCrC Coatings, J. Therm. Spray Technol. 25 (2016) 1302-1321.

[59] N. Cinca, J.M. Guilemany, Cold Gas Sprayed Stellite-6 Coatings and their Wear Resistance, J. Mater. Sci. Eng. 2 (2013) 1000122.

[60] G. Bolelli, B. Bonferroni, J. Laurila, L. Lusvarghi, A. Milanti, K. Niemi, P. Vuoristo, Micromechanical properties and sliding wear behaviour of HVOF-sprayed Fe-based alloy coatings, Wear 276-277 (2012) 29-47.

[61] M.F. Ashby, J. Abulawi, H.S. Kong, Temperature Maps for Frictional Heating in Dry Sliding, Tribol. Trans. 34 (1991) 577-587.

[62] Matweb datasheet: Corundum, Aluminum Oxide, Alumina, 99.9\%, $\mathrm{Al}_{2} \mathrm{O}_{3}$. http://www.matweb.com/search/DataSheet.aspx?MatGUID=c8c56ad547ae4cfabad159 77bfb537f1\&ckck=1 (accessed September 2, 2017).

[63] J.A. Garcia, A. Mandelis, B. Farahbakhsh, C. Lebowitz, I. Harris, Thermophysical Properties of Thermal Sprayed Coatings on Carbon Steel Substrates by Photothermal Radiometry, Int. J. Thermophys. 20 (1999) 1587-1602.

[64] G. Straffelini, Friction and Wear: Methodologies for Design and Control, Springer International Publishing AG, Cham, Switzerland, 2015.

[65] G. Bolelli, L. Lusvarghi, R. Giovanardi, A comparison between the corrosion resistances of some HVOF-sprayed metal alloy coatings, Surf. Coatings Technol. 202 (2008) 47934809.

[66] G. Bolelli, L. Lusvarghi, M. Barletta, Heat treatment effects on the corrosion resistance of some HVOF-sprayed metal alloy coatings, Surf. Coatings Technol. 202 (2008) 4839_ 4847. 


\section{Figures}
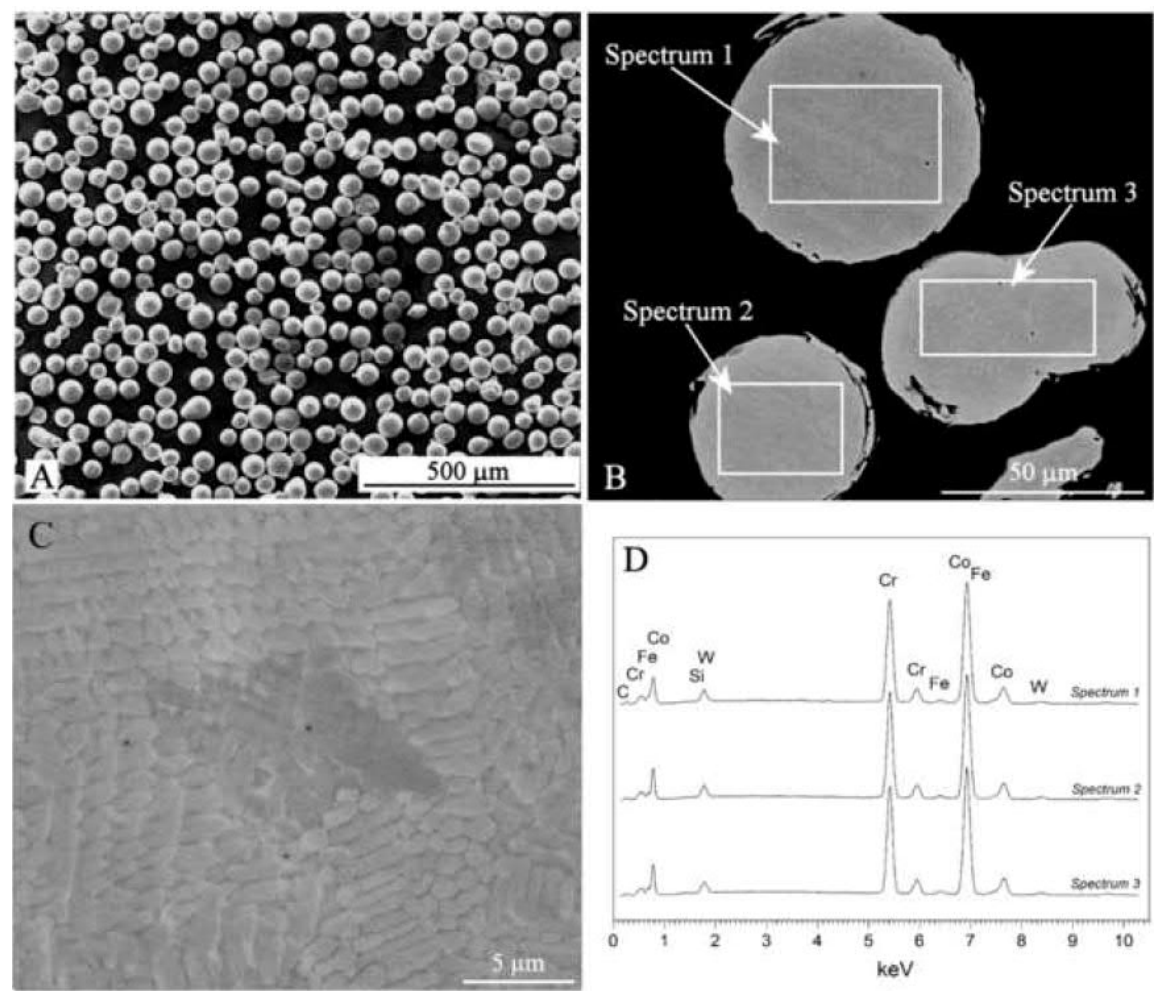

Figure 1. (A) SEM micrograph of the surface of the feedstock powder; (B) cross-sectional view of the same; (C) detail of the dendritic microstructure of a particle; (D) EDX spectra acquired at the locations marked in panel (B). 


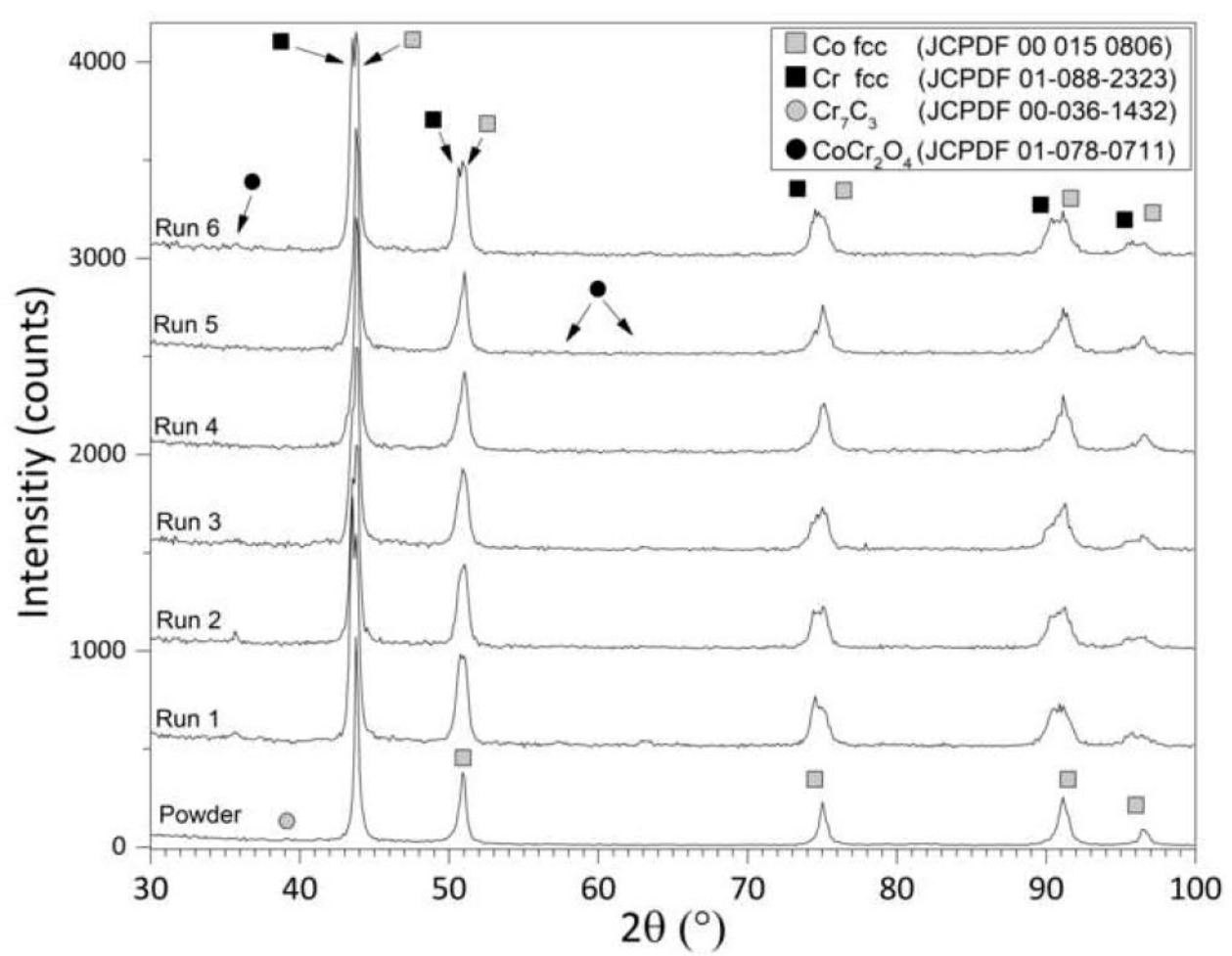

Figure 2. XRD patterns of the raw powder and of the coatings in as sprayed conditions.

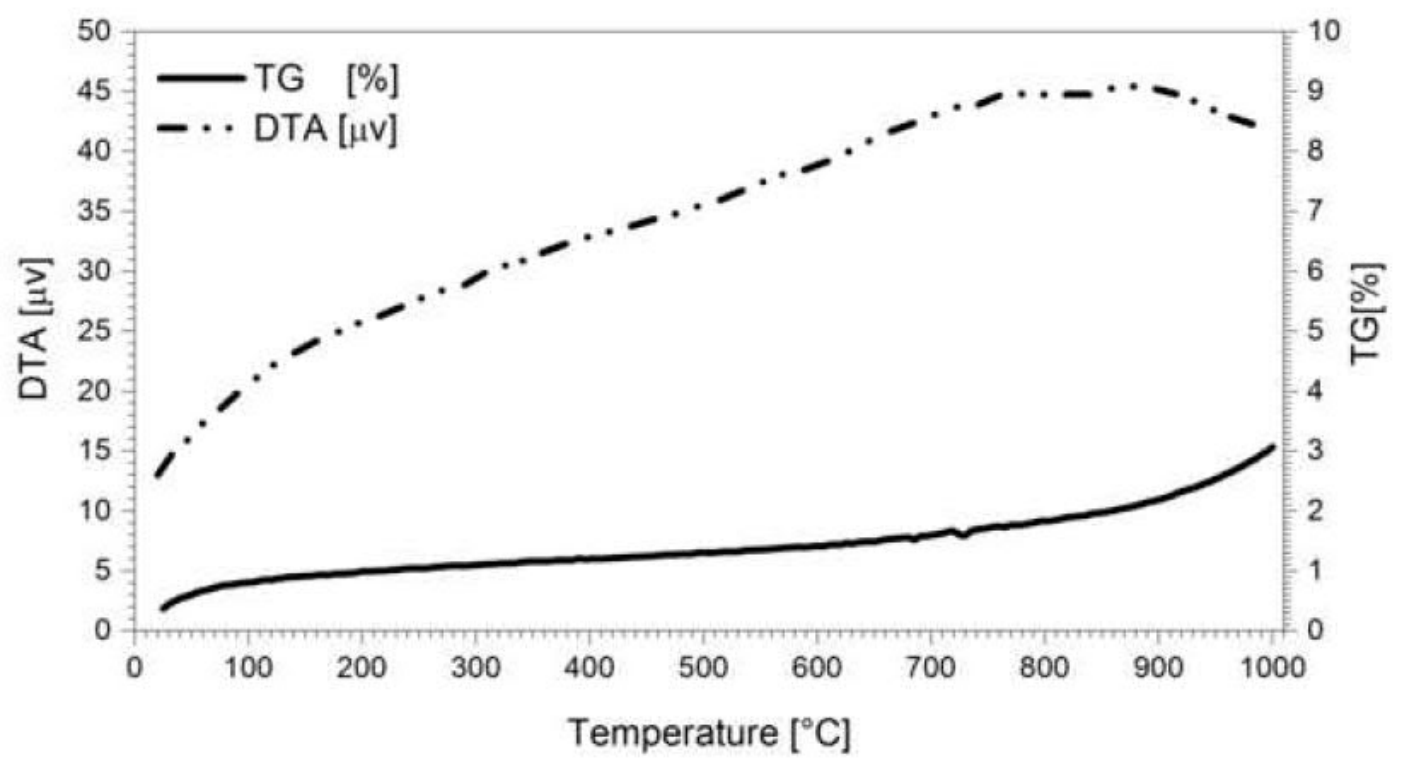

Figure 3. TG-DTA analysis of the Stellite 6 powder. 


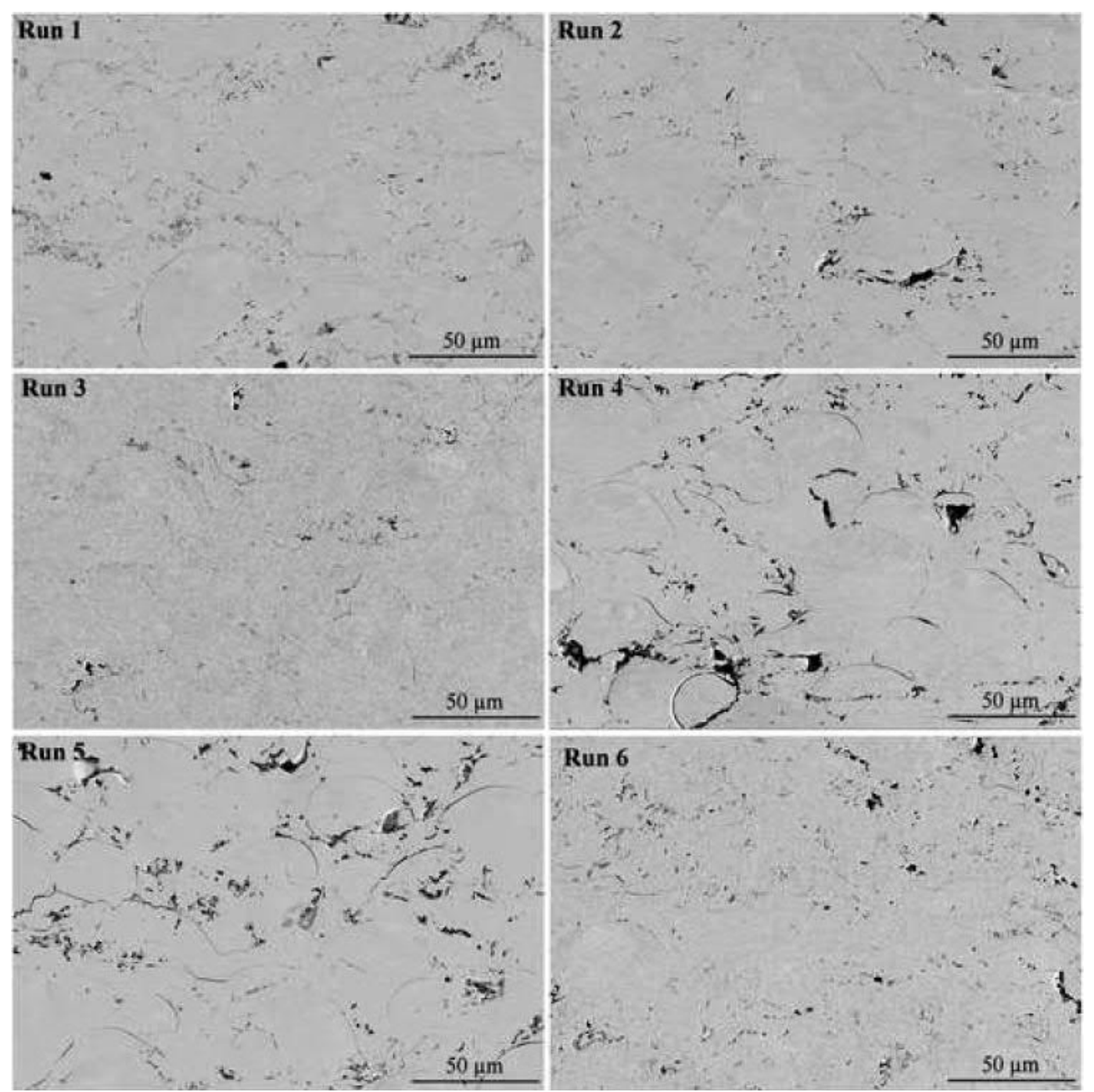

Figure 4. FE-SEM micrographs of the cross section of the coatings at 2000X magnification. 

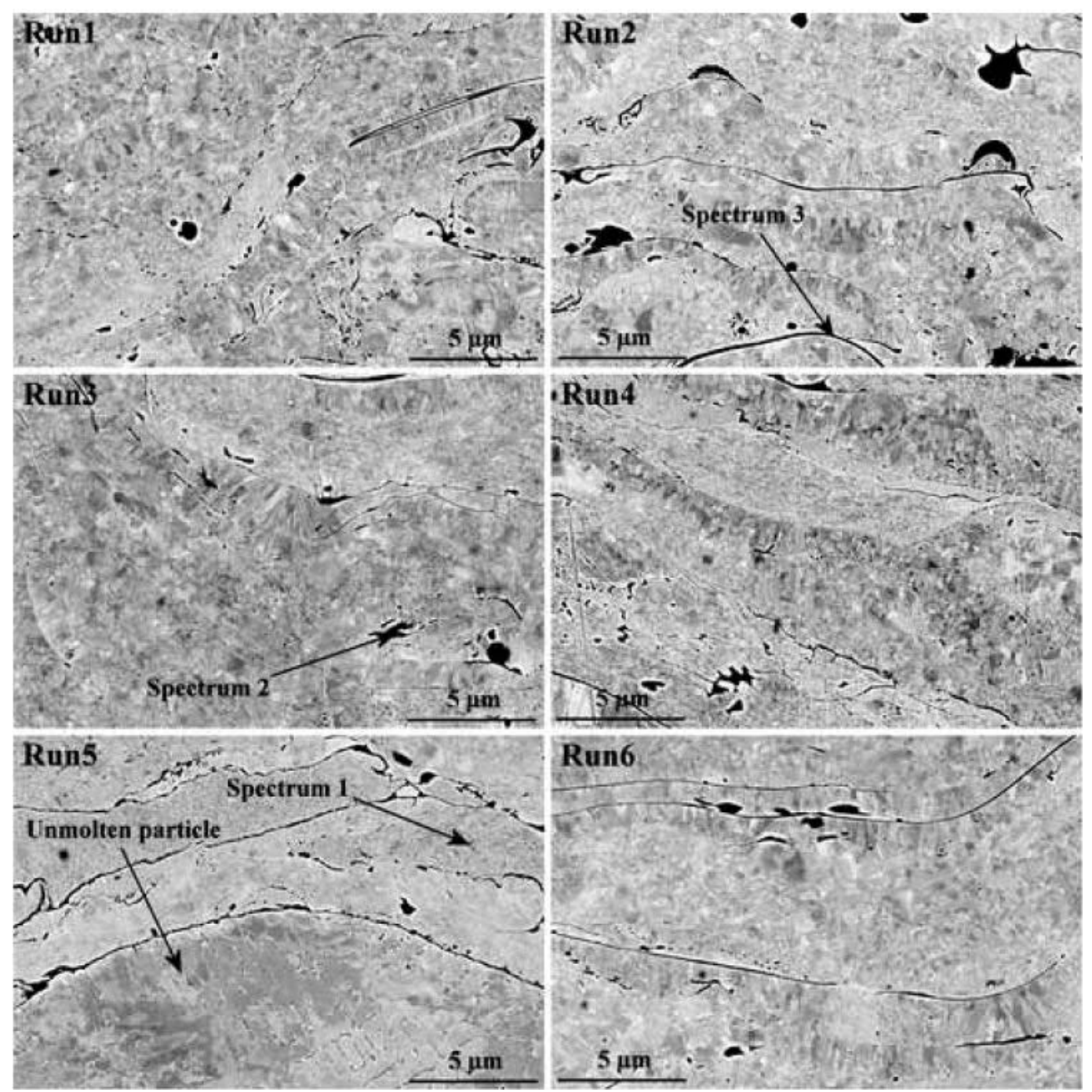

Figure 5. Detailed FE-SEM backscattered electron micrographs of the coating cross sections.
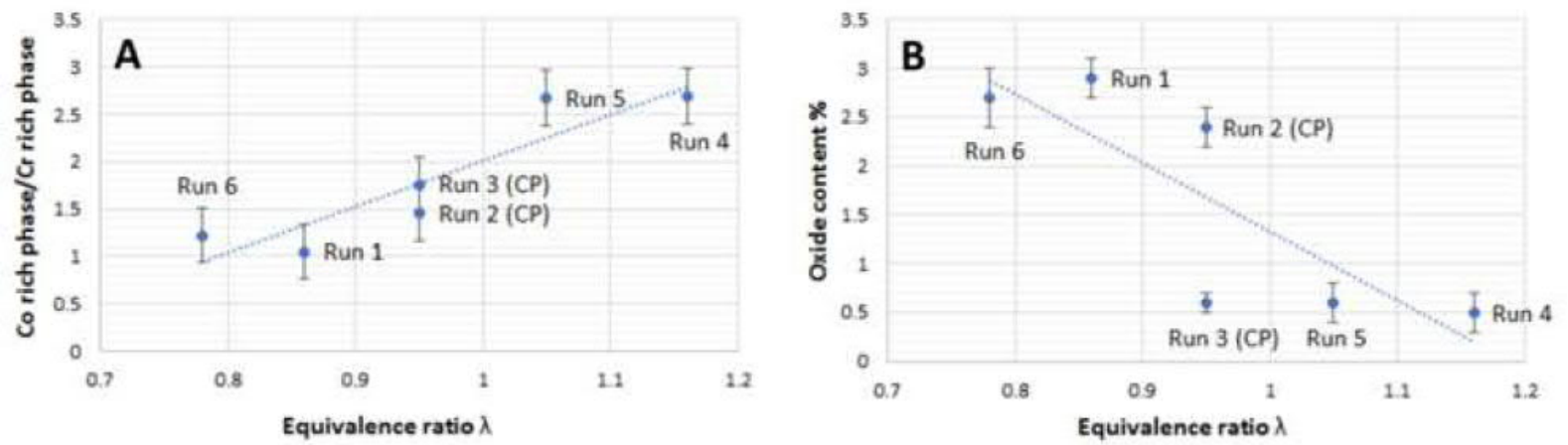

Figure 6. Results of the quantitative phase analysis by Rietveld refinement: (A) ratio between Co-rich and Cr-rich f.c.c. phases as a function of the equivalence ratio; (B) Oxide content in wt. $\%$ as a function of the equivalence ratio. 


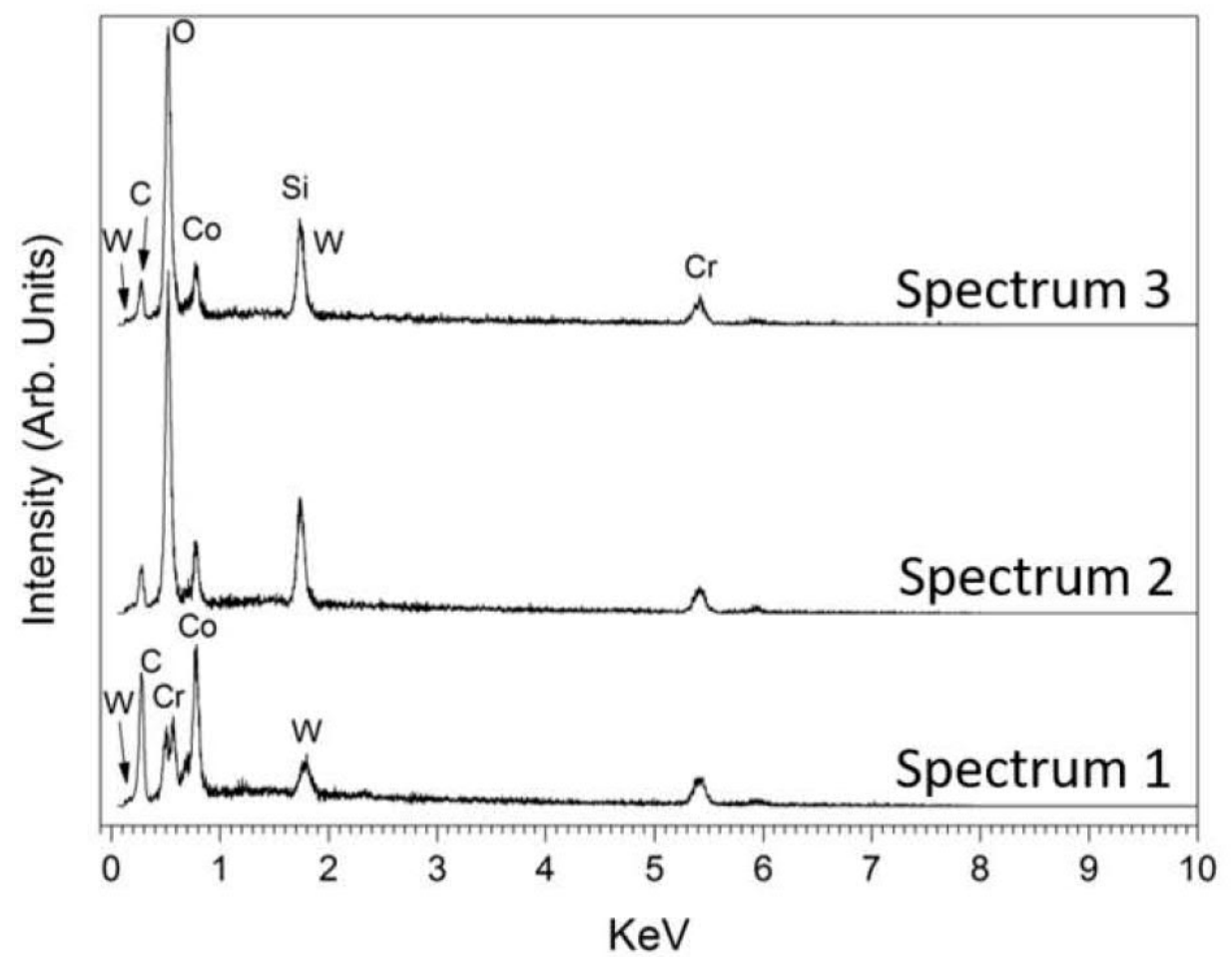

Figure 7. EDX spectra acquired in the positions pointed in Figure 5.

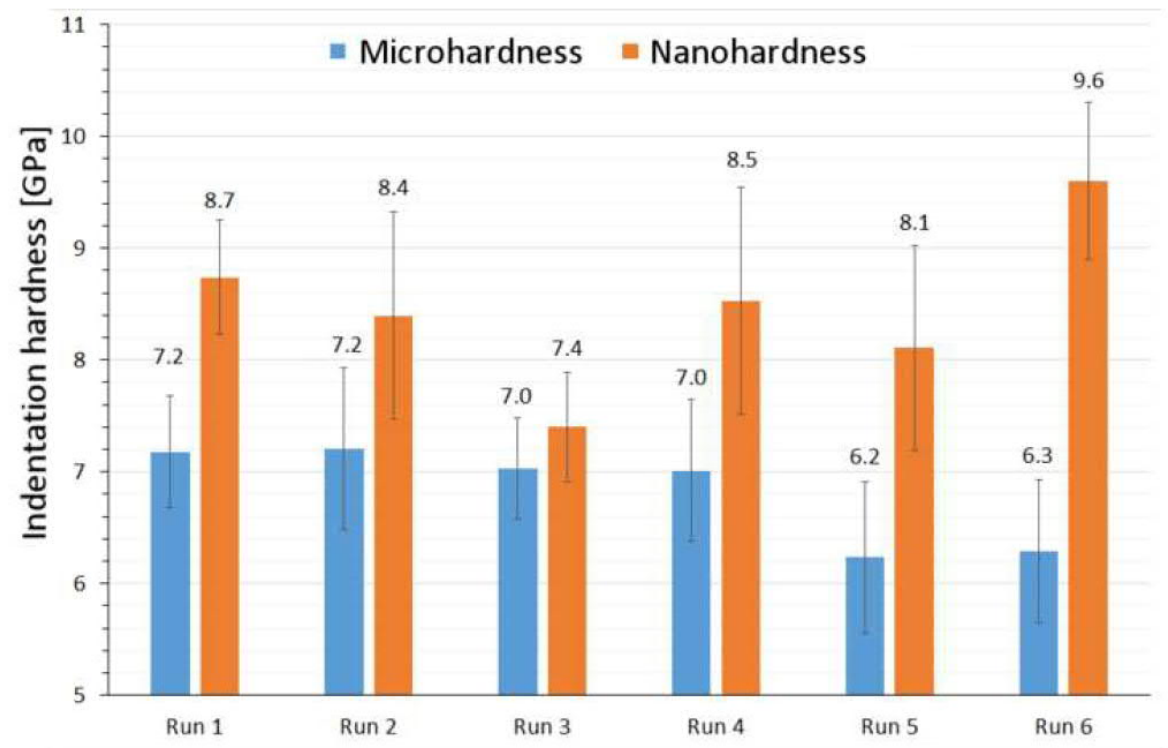

Figure 8. Micro- and nano-hardness of all coatings. 


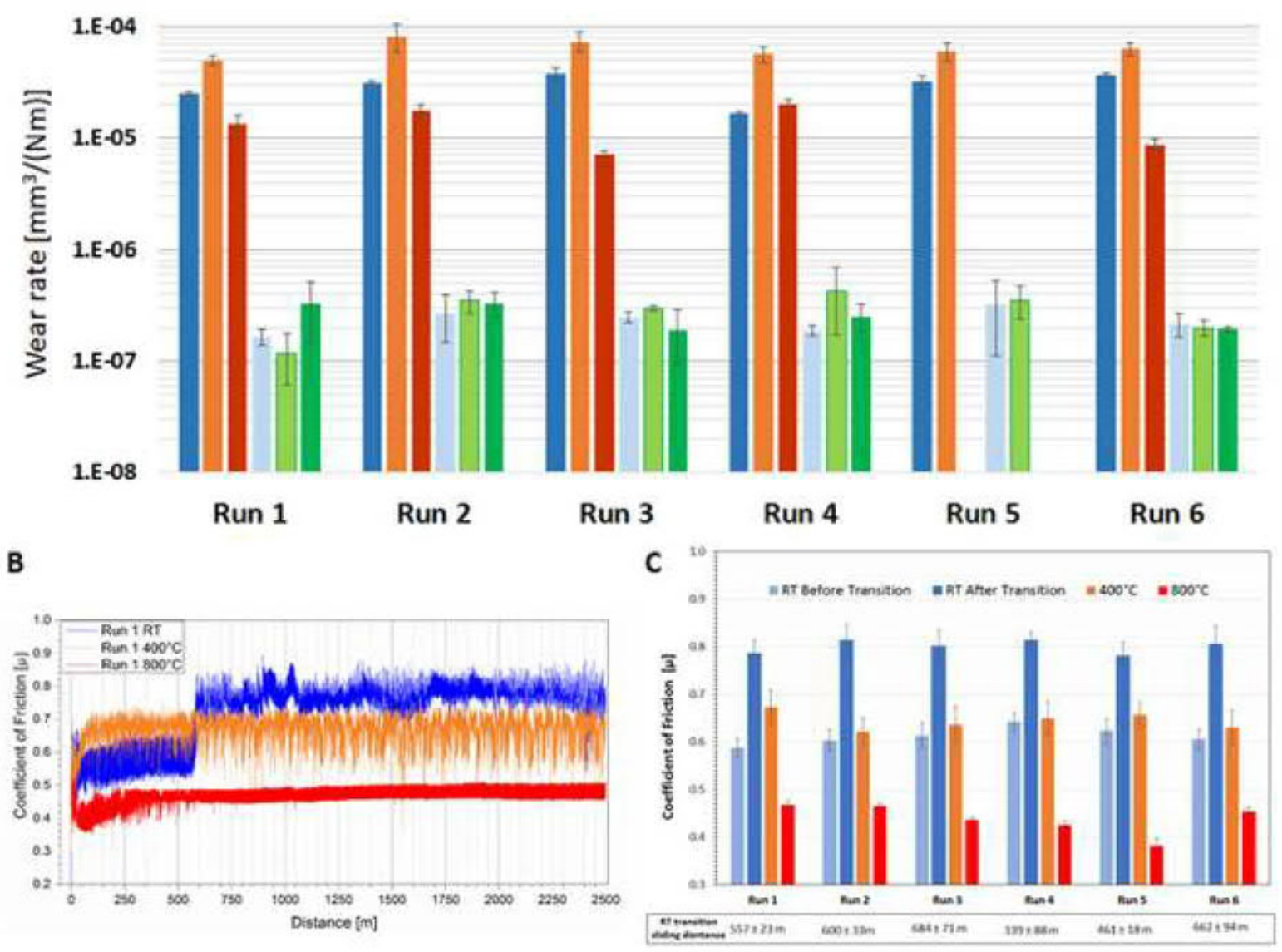

Figure 9. Results of the dry sliding ball-on-disk tests: (A) wear rates of samples and counterparts measured at room temperature $\left(\approx 25^{\circ} \mathrm{C}\right), 400{ }^{\circ} \mathrm{C}$ and $800{ }^{\circ} \mathrm{C}$; (B) friction curves measured on sample Run 1 at RT, $400{ }^{\circ} \mathrm{C}$ and $800^{\circ} \mathrm{C}$; (C) average friction coefficient measured at RT (before and after the transition), $400^{\circ} \mathrm{C}$ and $800^{\circ} \mathrm{C}$. 

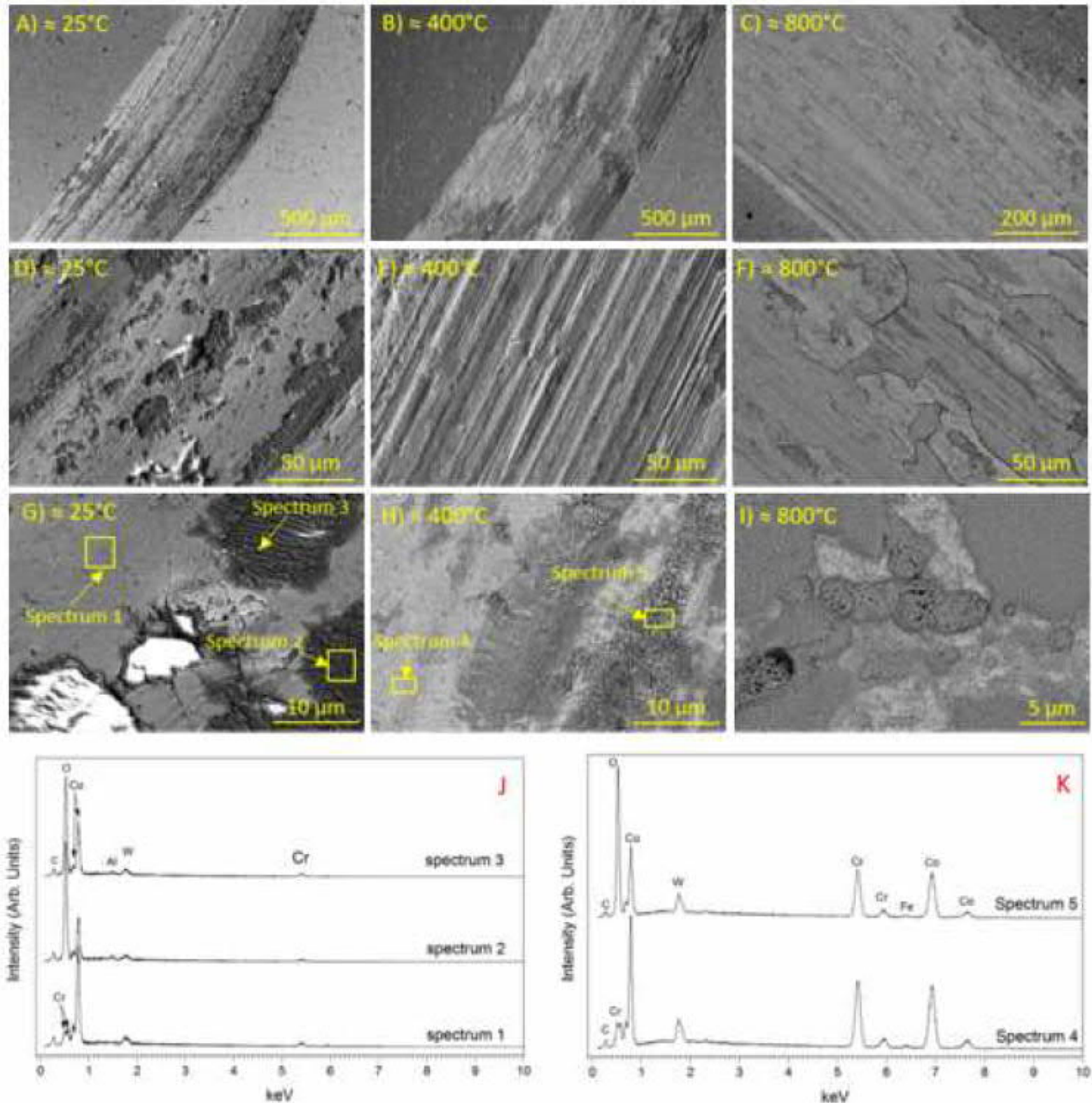

Figure 10. FE-SEM micrographs at different magnifications of the wear traces of sample Run6, tested at room temperature (A, D and G), $400{ }^{\circ} \mathrm{C}(\mathrm{B}, \mathrm{E}$ and $\mathrm{H})$ and $800{ }^{\circ} \mathrm{C}(\mathrm{C}, \mathrm{F})$, and of the oxide scale formed outside the wear trace at $800{ }^{\circ} \mathrm{C}(\mathrm{I})$, and EDX spectra $(\mathrm{J}, \mathrm{K})$ acquired at the locations marked in panels $\mathrm{G}$ and $\mathrm{H}$. 


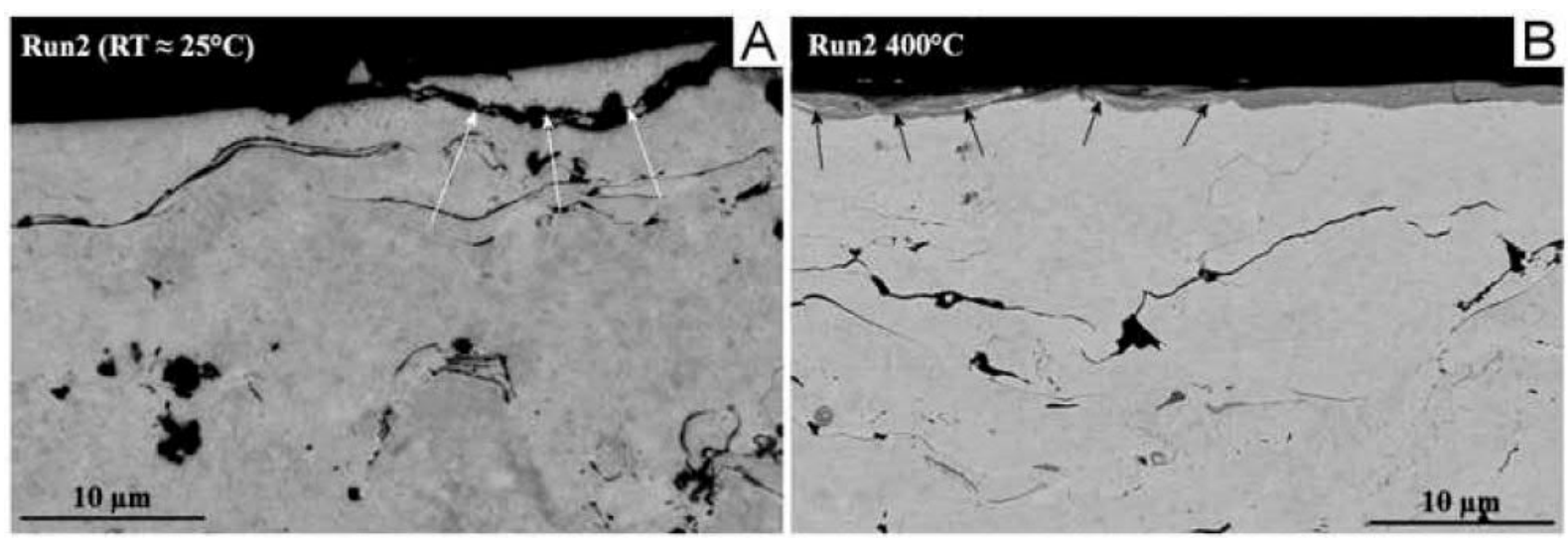

Figure 11. FE-SEM backscattered electron details of the cross sections of the wear tracks on coating Run3 tested at room temperature (A) and $400{ }^{\circ} \mathrm{C}(\mathrm{B})$.

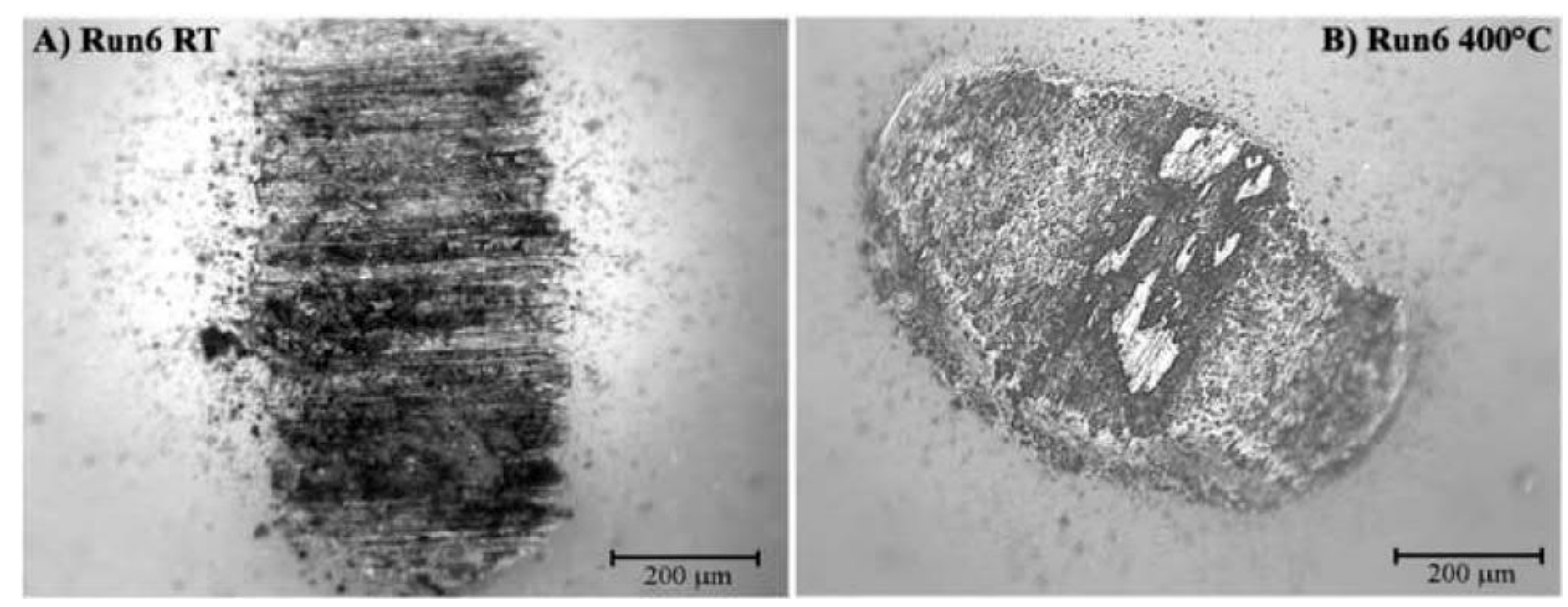

Figure 12. Optical micrographs of $\mathrm{Al}_{2} \mathrm{O}_{3}$ counterparts used against sample Run6 at room temperature (A) and $400^{\circ} \mathrm{C}(\mathrm{B})$. 


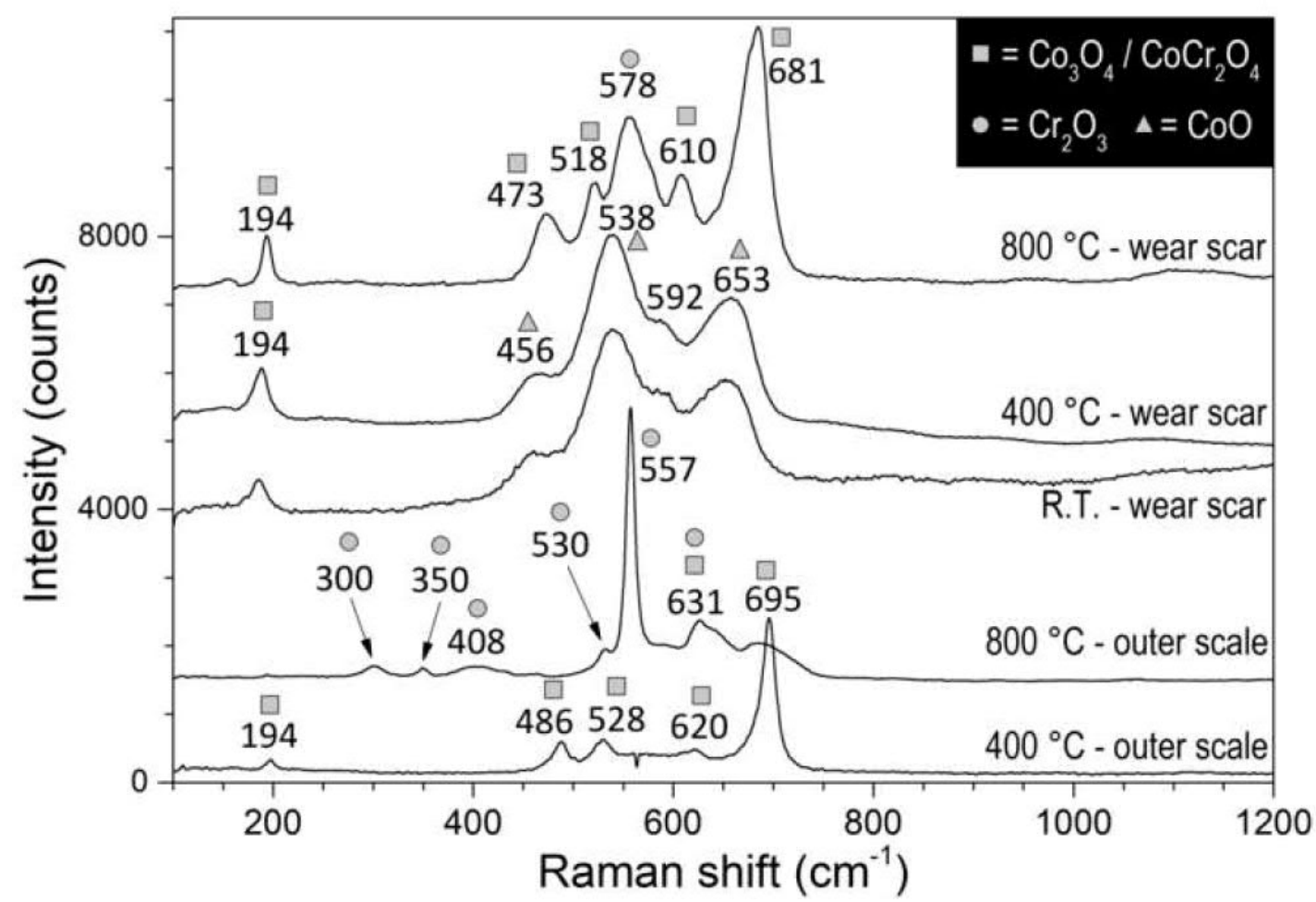

Figure 13. Micro-Raman spectra acquired on the oxide clusters found on the wear tracks of sample Run2 at room temperature and at $400{ }^{\circ} \mathrm{C}$, on the "glaze" tribofilm formed at $800{ }^{\circ} \mathrm{C}$, and on the oxide scale formed spontaneously outside the wear track at $400{ }^{\circ} \mathrm{C}$ and at $800{ }^{\circ} \mathrm{C}$. 


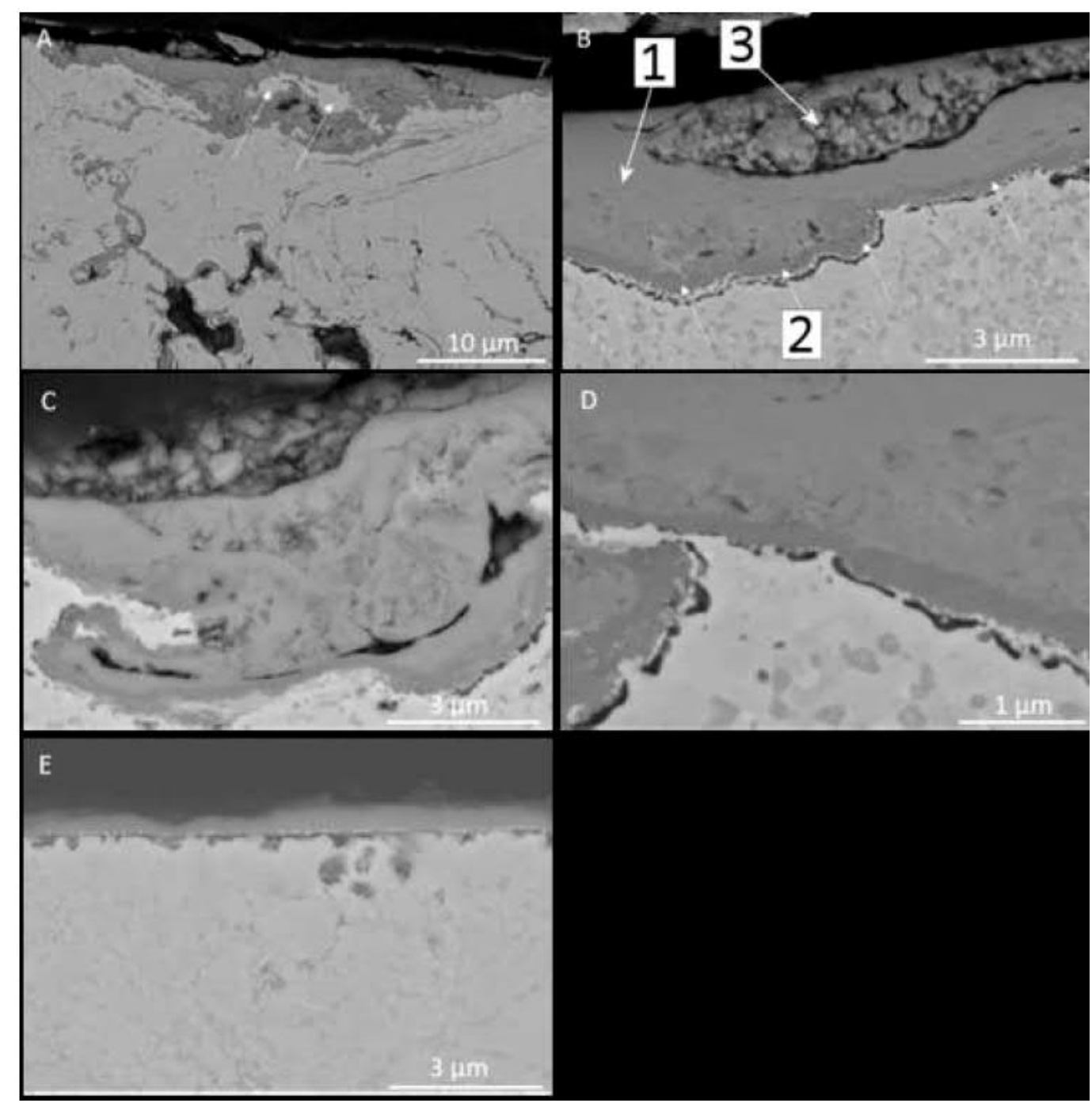

Figure 14. Cross section of the Stellite coating after sliding wear testing at $800{ }^{\circ} \mathrm{C}$ : overview (A), details of the "glaze" tribofilm (B,C) and of its interface with the underlying metal (D), and detail of the oxide scale formed spontaneously outside the wear track (E). 


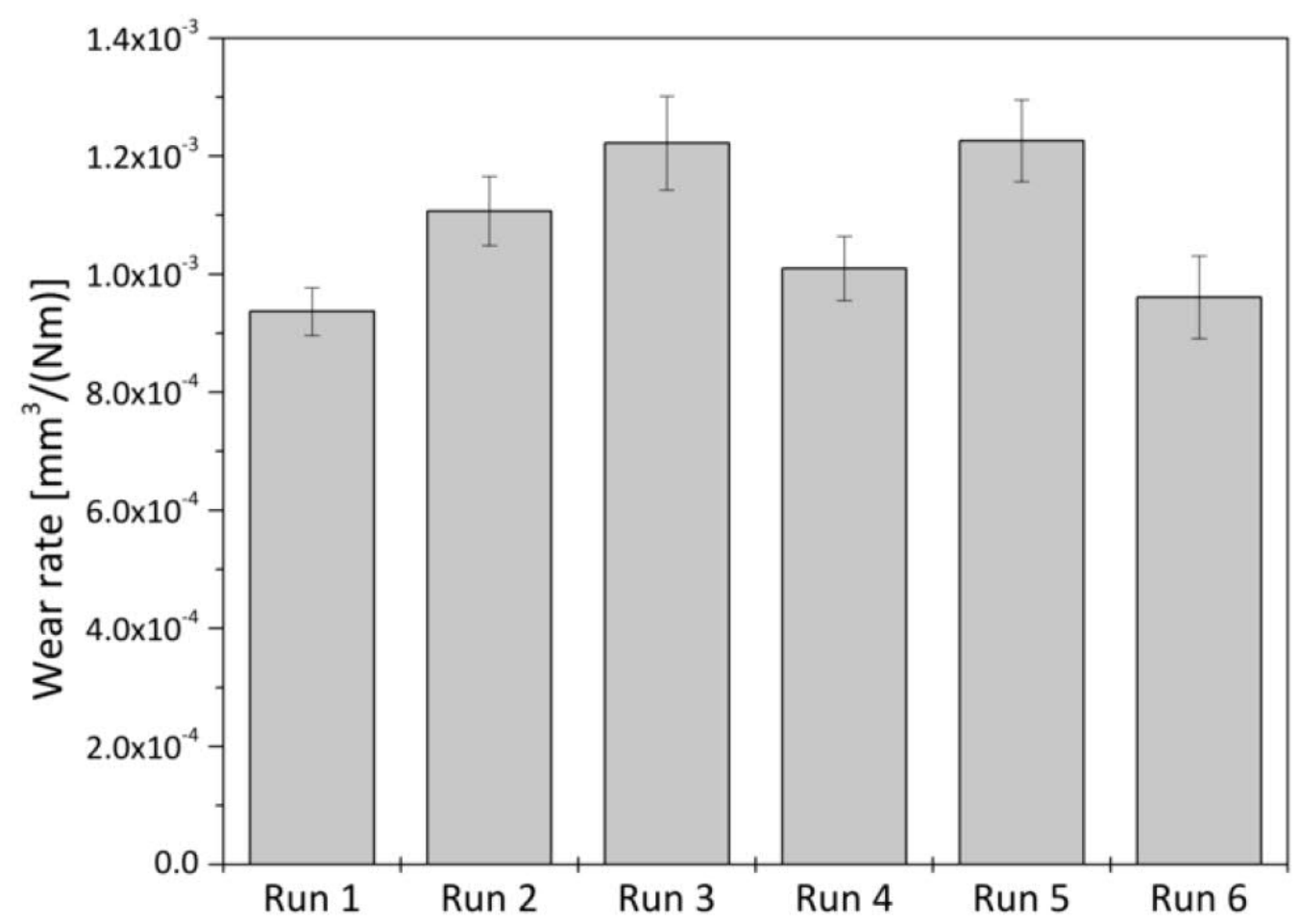

Figure 15. Wear rates of Stellite-6 coatings measured after the dry sand-steel wheel test.
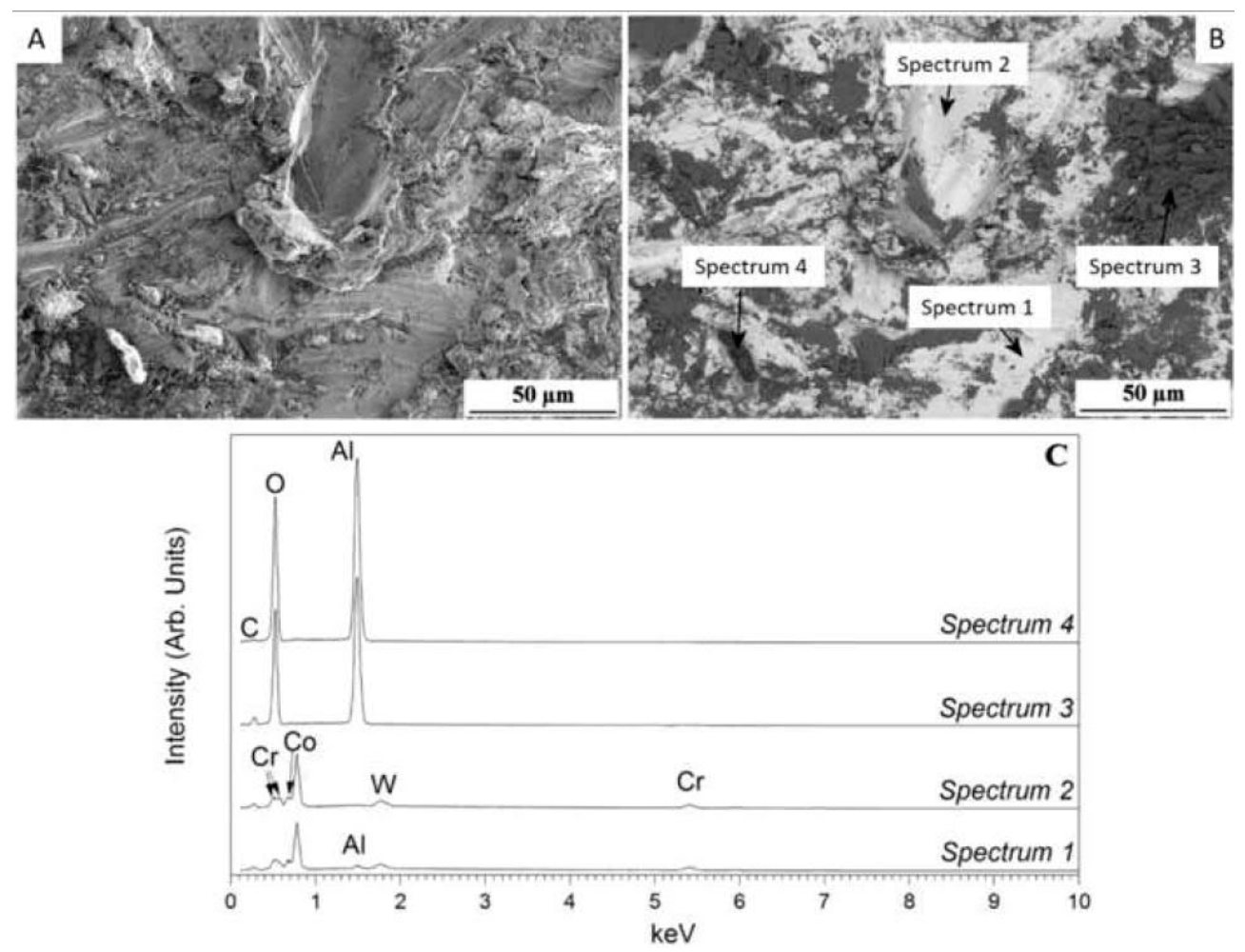

Figure 16. FE-SEM micrographs of the wear scar after dry sand-steel wheel testing of sample Run 6, in secondary electrons (A) and backscattered electrons (B) imaging mode; (C) EDX microanalysis acquired in the areas marked in panel $\mathrm{B}$. 


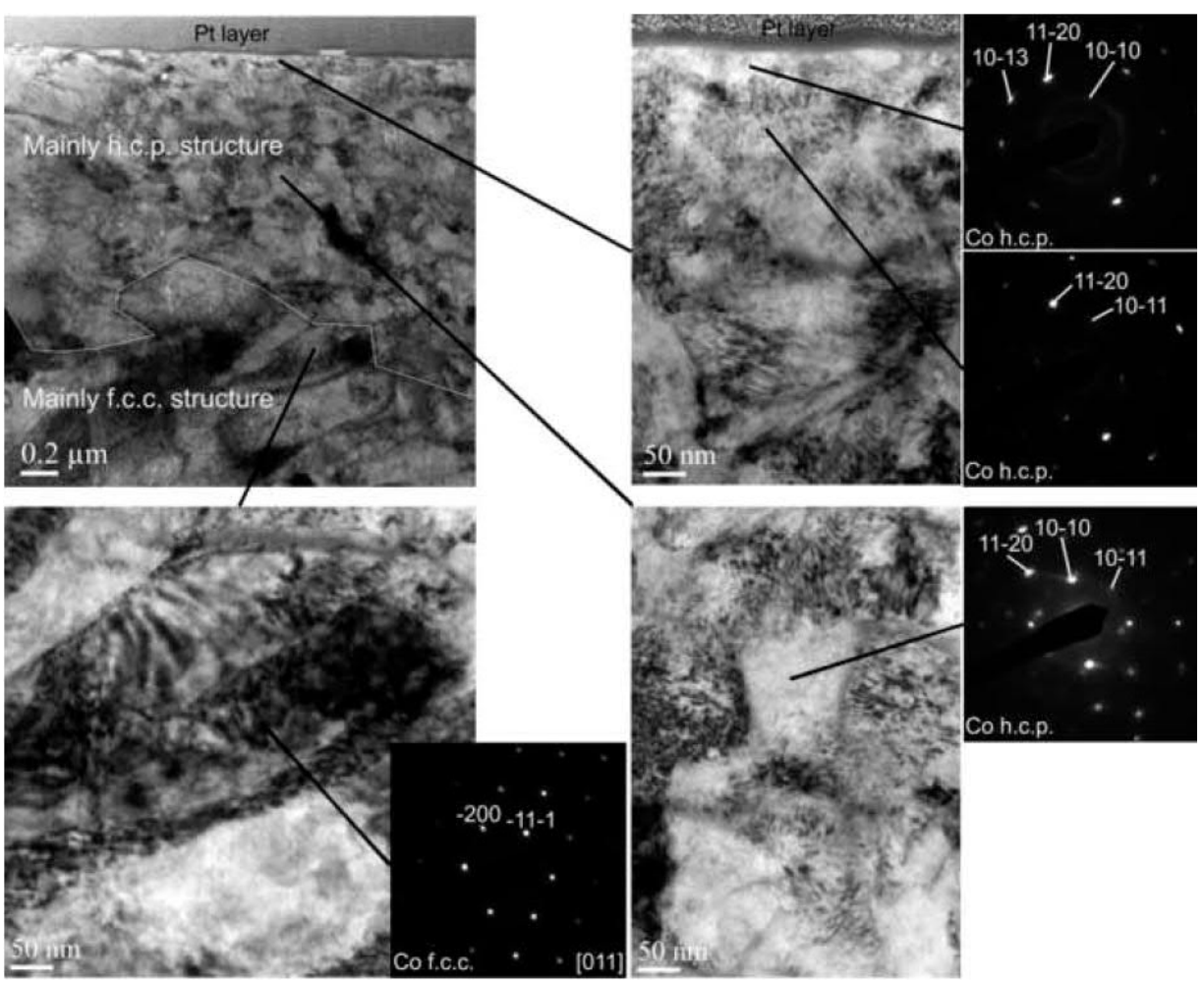

Figure 17. The BF TEM images and SAED patterns of the sample from inside the wear track. The higher magnification images and SAED patterns were collected next to coating surface and below the coating surface. The SAED patterns indicate a 1-2 $\mu \mathrm{m}$ surface layer with Cobased h.c.p. structure (indexed according to JCPDF 1-80-6668) and a deeper area with f.c.c. structure (indexed according to JCPDF 15-0806). 


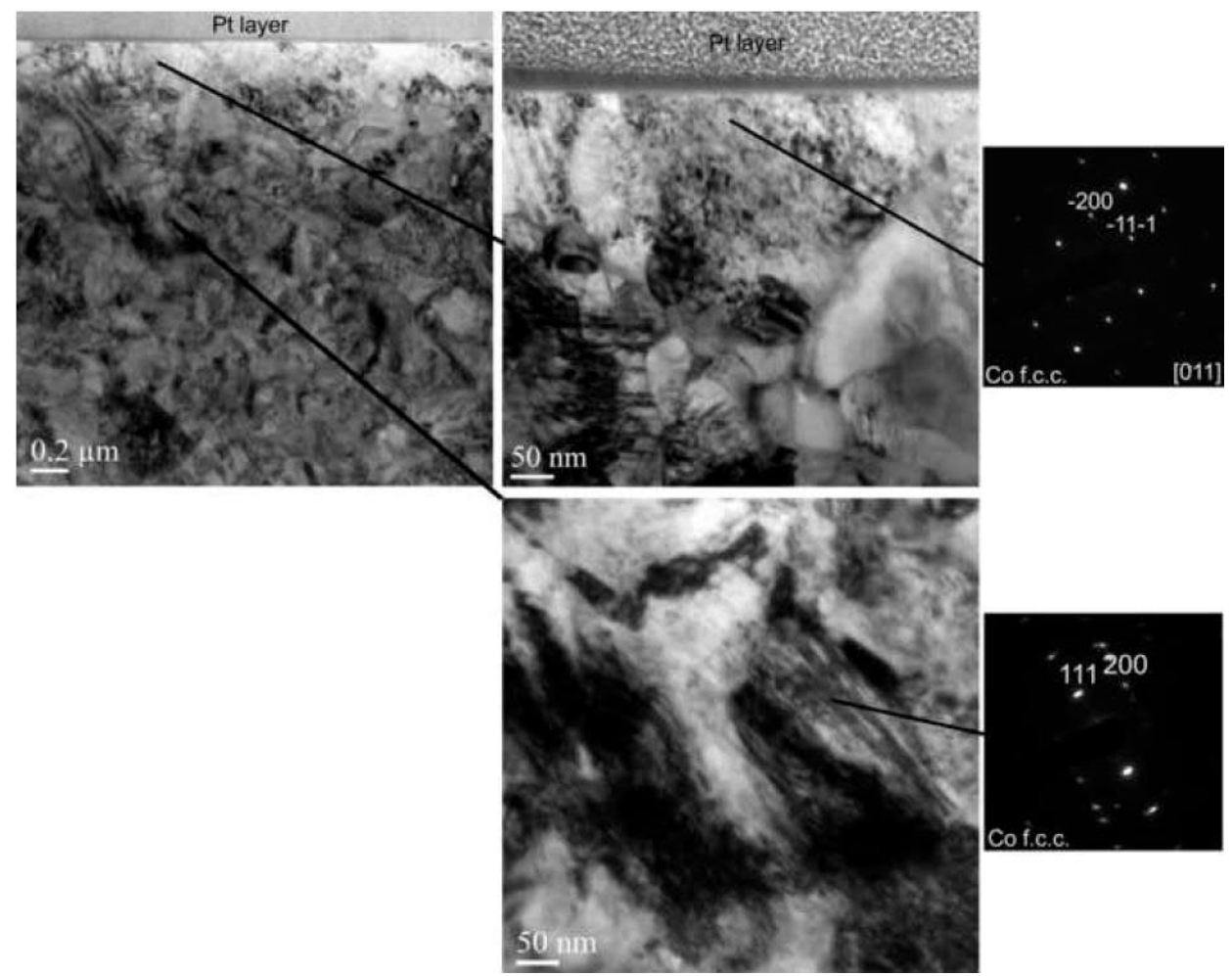

Figure 18. The BF TEM images and SAED patterns of the sample from outside the wear track. The higher magnification images and SAED patterns were collected next to the coating surface and from a depth of $\sim 1 \mu \mathrm{m}$ below the coating surface. The SAED patterns indicate the Co-based f.c.c. structure (indexed according to JCPDF 15-0806).
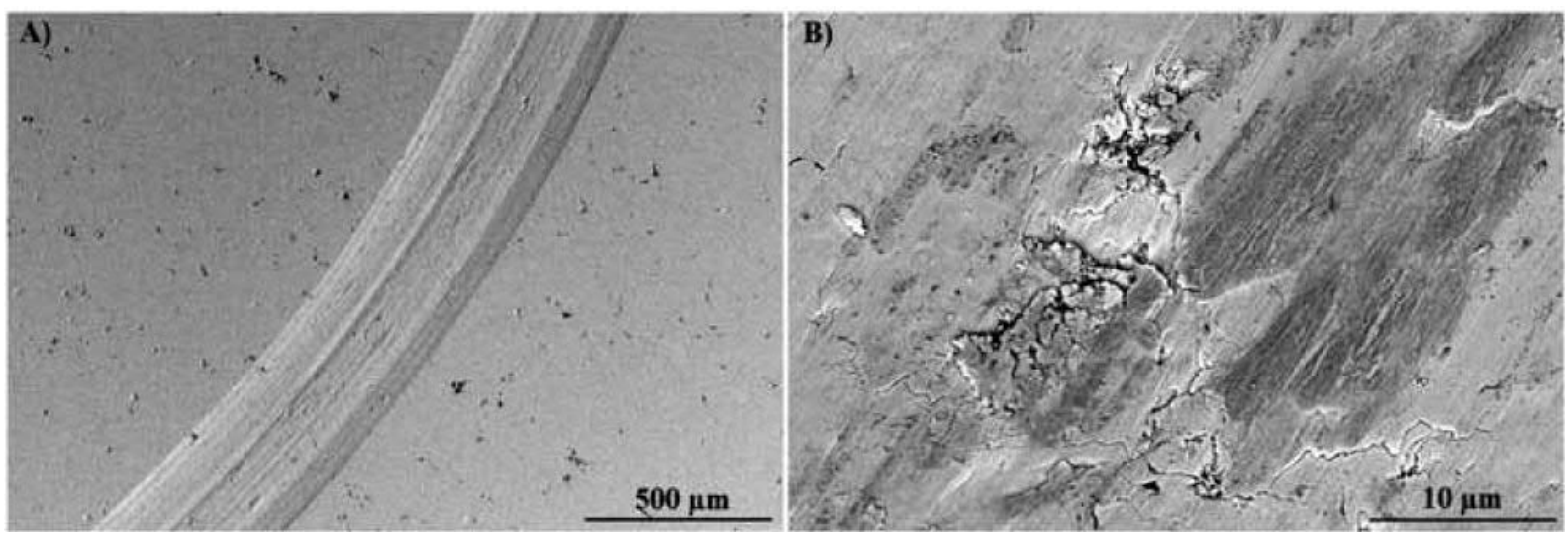

Figure 19. FESEM micrographs of the short sliding ball-on-disk test (100m) wear track: (A) overview; (B) detail. 


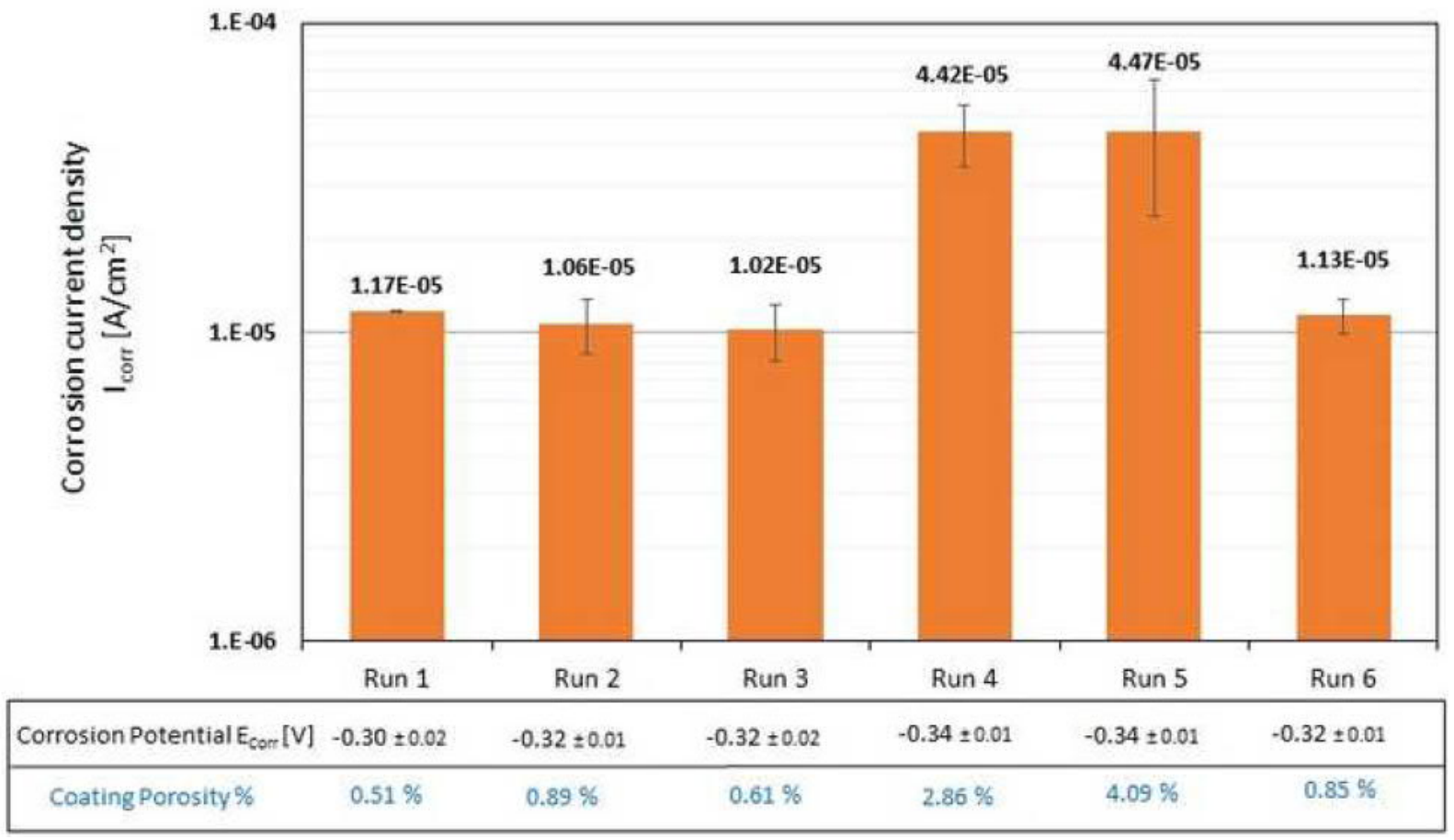

Figure 20. Corrosion current density ( $\left.\mathrm{I}_{\mathrm{Corr}}\right)$ and corrosion potential ( $\left.\mathrm{E}_{\mathrm{Corr}}\right)$ measured on the Stellite-6 coatings deposited with different spraying parameters.

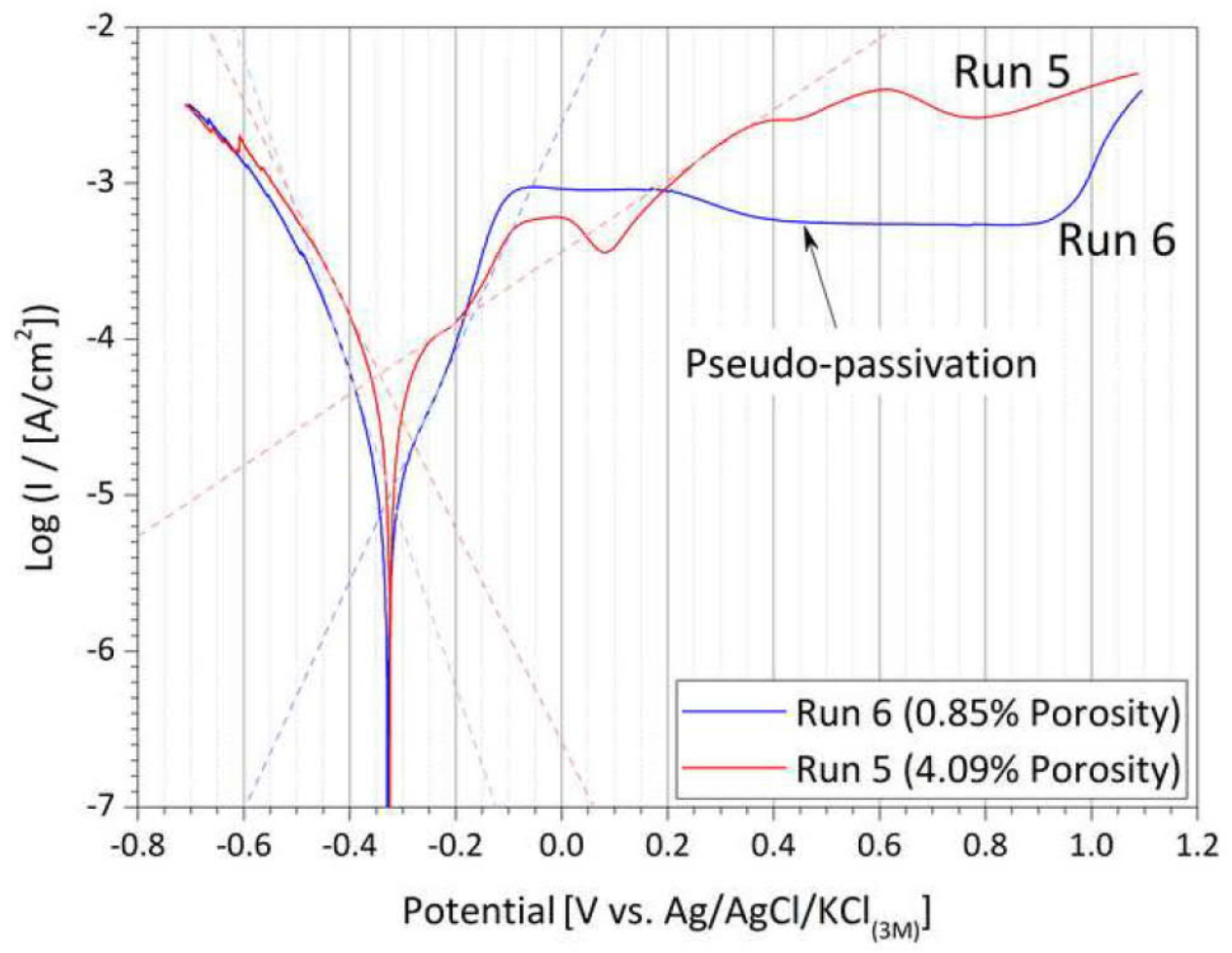

Figure 21. Plot of the electrochemical polarization curves $-E$ vs. $\log (\mathrm{I})-$ acquired on the Stellite- 6 coatings Run 5 and Run 6. 


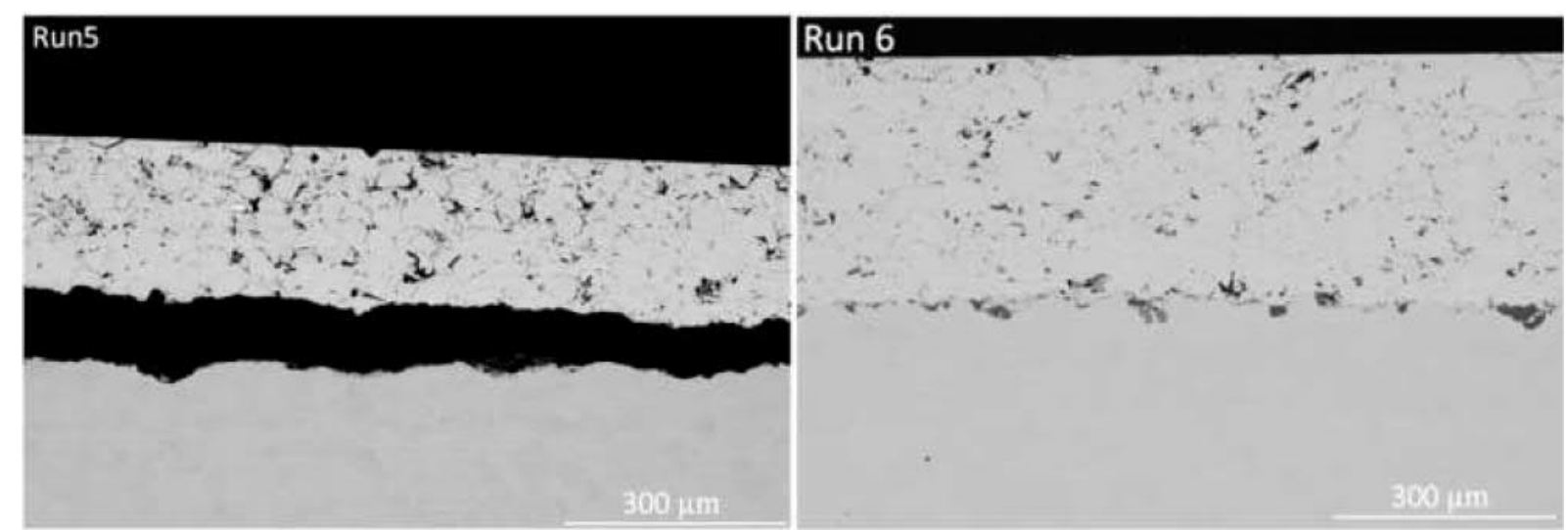

Figure 22. FE-SEM micrographs of the cross sections of coatings Run5 and Run6 after the electrochemical polarization test.

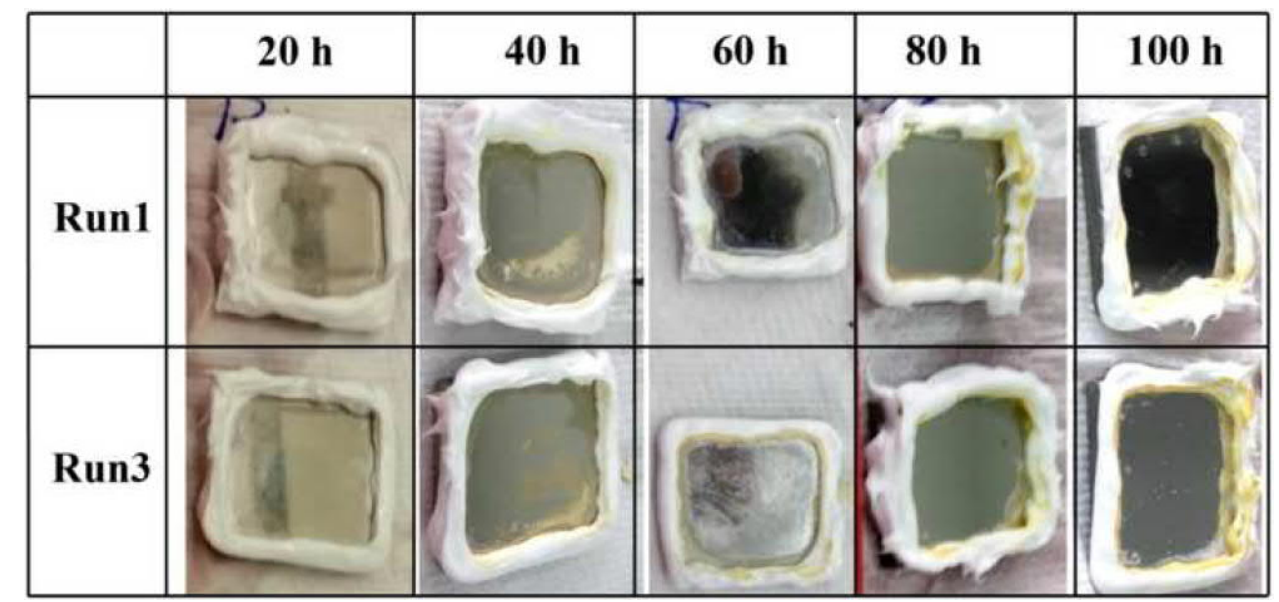

Figure 23. Photographs of samples Run1 and Run3 after each 20 hour-cycle of Corrodkote testing, after removal of the corrosive slurry. 
Tables

Table 1. Deposition parameters of Stellite-6 as a screening factorial design.

\begin{tabular}{|c|c|c|c|c|}
\hline Experiment label & $\begin{array}{c}\text { Powder feed } \\
\text { rate (g/min) }\end{array}$ & $\begin{array}{c}\text { Oxygen flow } \\
\text { rate (SLPM) }\end{array}$ & $\begin{array}{c}\text { Hydrogen flow } \\
\text { rate (SLPM) }\end{array}$ & $\begin{array}{c}\text { Equivalence } \\
\text { ratio } \lambda\end{array}$ \\
\hline Run1 & 80 & 214 & 635 & 0.88 \\
\hline Run2 $($ C.P) & 60 & 201 & 553 & 0.96 \\
\hline Run3 (C.P) & 60 & 201 & 553 & 0.96 \\
\hline Run4 & 40 & 214 & 471 & 1.19 \\
\hline Run5 & 80 & 188 & 471 & 1.07 \\
\hline Run6 & 40 & 188 & 635 & 0.80 \\
\hline
\end{tabular}


Table 2. Constant deposition parameters.

\begin{tabular}{|c|c|}
\hline Parameter & Value \\
\hline Air flow rate (SLPM) & 313 \\
\hline Air pressure (psi / MPa) & $100 / 0.689$ \\
\hline Oxygen pressure (psi / MPa) & $170 / 1.172$ \\
\hline Hydrogen Pressure (psi / MPa) & $140 / 0.965$ \\
\hline Spraying distance (mm) & 250 \\
\hline Spray angle & $90^{\circ}$ \\
\hline Torch traverse speed (m/s) & 3000 \\
\hline Pass spacing (mm) & 6 \\
\hline Number of cycles & 24 \\
\hline
\end{tabular}


Table 3. Average values of thickness and porosity of Stellite- 6 coatings.

\begin{tabular}{|c|c|c|c|c|c|c|}
\hline & Run 1 & Run 2 & Run 3 & Run 4 & Run 5 & Run 6 \\
\hline Thickness $[\mu \mathrm{m}]$ & $885 \pm 14$ & $701 \pm 11$ & $665 \pm 26$ & $276 \pm 16$ & $426 \pm 12$ & $491 \pm 8$ \\
\hline Porosity $[\%]$ & $0.51 \pm 0.20$ & $0.89 \pm 0.39$ & $0.61 \pm 0.27$ & $2.86 \pm 0.71$ & $4.09 \pm 0.89$ & $0.85 \pm 0.31$ \\
\hline
\end{tabular}

